\title{
A Review on Veterinary Drug Management, Handling, Utilization and Its Resistance Side Effects
}

\author{
Mengesha A* \\ University Of Gondar, Faculty of Veterinary Medicine, \\ Gondar, Ethiopia \\ *Corresponding author: Ayehu Mengesha, University \\ Of Gondar, Faculty of Veterinary Medicine, Gondar, \\ Ethiopia
}

Received: July 01, 2021; Accepted: J uly 22, 2021;

Published: July 29, 2021

\begin{abstract}
Veterinary drugs play an important role in the control and prevention of animal diseases and animal sufferings, however it have the potential to cause harm if it is not used properly. Successful animal health service provision needs the availability of safe, effective and affordable drugs of the required quality and quantity. The available drugs must be prescribed, presented, transported, dispensed, labeled, packaged, measured and used rationally. Rational use of drugs in veterinary medicine has manifold significance; it can be either public health significance, improve food safety concern, reduce the development of drug resistance and residue or economic significance; the need to rely on more expensive drugs and international trade barrier. The potential public health hazard as a result of irrational drug use in food animals includes limited efficacy, increase risk of unwanted effects such as the emergence of drug resistance and drug residue, waste of resources and psychosocial impacts. Irrational drug using is characterized by over-prescription, inappropriate dosage, incorrect duration and unnecessary risk. There are several reasons which may contribute to irrational use of drugs. Some of them are lack of information, inadequate training and education of graduates of veterinary medicine, poor communication between veterinarian and owner, lack of diagnostic facilities, demand from the animal owner, and promotional activities of pharmaceutical industries. This paper had induced to document and aware procedures and necessary activities to have rational drug use, and it would helps to have proper drug measurement and dose calculation as well as it tell us about Odrug resistance and its public health effects. Over all This review hoped that as it would be help to animal health professionals and enhance the quality of veterinary pharmaceutical services so that decrease the economic loss and public health hazard due to diseases of livestock and protects the impacts of drug resistance and its residue.
\end{abstract}

Keywords: Rational use; Prescription; Resistance; Irrational use

\section{Introduction}

Veterinary drugs or veterinary pharmaceuticals are substances in use to treat or prevent animal diseases for health, growth promotion and productivity [1]. The provision of successful animal health service requires the availability of safe, effective and affordable drugs of the required quality and quantity. In addition, the available drugs must be prescribed, presented, dispensed and used rationally. Proper utilization of veterinary drugs involves handling, prescribing, dispensing and delivery of drugs for the animal species under the proper supervision and involvement of veterinary professionals [2].

Rational veterinary drug use is the part of quality management system that guarantees the quality of the veterinary pharmaceuticals through controlling various activities related to storage, transportation, distribution, prescription and dispensing [3]. In other expression it is also prescribing and delivery of the correct veterinary drug to the right patient, in the required quantities, for an adequate period of time and at the lowest cost, in the package that maintains acceptable potency and quality for the specified period, with clear veterinary drug information counseling and appropriate follow up [4].

The use of veterinary drugs with doubtful efficacy, incorrect diagnosis, the use of veterinary drugs with uncertain safety status, use of correct veterinary drugs with incorrect route of administration, dosage, or duration, the storage of veterinary drugs with other materials in the institution store, absence of refrigerators for veterinary drugs that need cold chain, the dispensing of prescription only veterinary drugs at partial doses and without prescription, poor labeling of the dispensed items, lack of animal owner counseling, incomplete compiling and recording of prescriptions, and charging animal owner unreasonably high prices for the dispensed veterinary drug are some of the practices that reflect an irrational veterinary drug use $[2,4]$. Such improper utilization eventually decreases drug's efficacy, occurrence of therapeutic failure, harmful drug effects, and drug resistance. It is also a threat to human medicine since majority of drugs used in veterinary medicine are structurally related to human therapeutics which may select for co or cross resistance [5]. There are dispensing of veterinary drugs with other goods in the shops and markets, dispensing of prescription only veterinary drug without prescription, dispensing of veterinary drugs by non veterinary drug professionals in the veterinary pharmacy, dispensing of illegal veterinary drugs and veterinary drugs donated by nongovernmental organization with low price and unethical practices of professionals.

Creating and improving awareness about rational use of 
veterinary drugs is helpful to avoid all these misses [5]. Therefore, this review is issued as one means of promoting proper use of veterinary drugs. It will support animal health and veterinary drug professionals as source of information for rational veterinary drug.

Therefore, the objectives of this review paper out line are:

- To document sources and veterinary drug developments.

- Enhance and improve knowledge, skill, and attitude of animal health professionals on rational use of veterinary drugs.

- To document proper drug measurement and dose calculation.

- Improve awareness on the consequences of irrational veterinary drug use.

- $\quad$ Encourage professionals to promote ethical practices and Motivate professionals in developing and maintaining behaviour of regularly updating about veterinary drug.

\section{Literature Reviews}

\section{Sources of veterinary drugs}

Basically, there are six Sources of veterinary drugs; those are plants, microorganisms, animals, mineral and mineral products, synthetic or semi-synthetic substances and engineered sources $[2,6]$.

Plants: Most of the veterinary drugs in ancient times were derived from plants. Leave, stem, flower, bark, fruit and root just almost all parts of the plants are used to extract drugs. About $25 \%$ of the drugs prescribed worldwide are originated from plants. From the total 252 drugs considered as basic or essential by the World Health Organization (WHO), 11\% are exclusively of plant origin. Chemicals obtained from plants such as alkaloid, tannins, resins, glycoside, oil, gum, mucilage, carbohydrate and related compounds are used as a drug or may also be added as vehicle [6].

Plants also play a great role to be the potential sources for new drug discovery in the future drug development. A leaf of Atropa belladonna gives atropine; the leaves of Digitalis purpurea are the source of Digitoxin and Digoxin, which are cardiac glycosides. A Flowers of Poppy papaver somniferum gives morphine;Rose gives rose water used as tonic [2]. A Fruits of Senna pod gives anthracine, which is a purgative (used in constipation), Calabar beans give physostigmine, which is cholinomimetic agent. Seeds of Nux vomica give strychnine, which is a CNS stimulant, Castor oil seeds give castor oil, which is used as laxative, Calabar beans give Physostigmine, which is a cholimimetic drug. A Roots of Ipecacuanha gives emetine, used to induce vomiting as in accidental poisoning. It also has amoebicidal properties. Rauwolfia serpentina gives reserpine, a hypotensive agent. Bark of Atropa belladonna gives atropine, which is anticholinergic. Hyoscyamus niger gives hyosine, which is also anticholinergic. Stem of Chondrodendron tomentosum gives tuboqurarine, which is skeletal muscle relaxant, used in general anaesthesia $[2,4,6]$.

Microorganisms: Microorganisms like fungi, moulds and bacteria are important sources for veterinary drugs, among those drugs they are listed below as shown on the Table 1 .

Animals: Drugs coming from animals are not usually pure and may contain antigens which induce allergic reactions. The drugs which

Table 1: Microorganism used as the source of antibiotics.
\begin{tabular}{|r|l|l|}
\hline S/n & \multicolumn{1}{|c|}{ Microorganism } & \multicolumn{1}{|c|}{ Antibiotic } \\
\hline 1 & Bacillus subtilis & Bacitracin \\
\hline 2 & Bacillus polymyxa & Polymyxin \\
\hline 3 & Streptomyces nodosus & Amphotericin B \\
\hline 4 & Streptomyces venezuelae & Chloramphenicol \\
\hline 5 & Streptomyces aureofaciens & Tetracycline/chlortetracycline \\
\hline 6 & Streptomyces erythraeus & Erythromycin \\
\hline 7 & Streptomyces griseus & Streptomycin \\
\hline 8 & Micromonospora purpureae & Gentamicin \\
\hline 9 & Cephalosporium species & Cephalothin \\
\hline 10 & Penicillium griseofulvum & Griseofulvin \\
\hline 11 & Penicillium notatum & Penicillin \\
\hline
\end{tabular}

are coming from animals include Insulin which is extracted from pancreas, used in treatment of Diabetes mellitus; Human chorionic gonadotropin obtained from urine of pregnant women used for the treatment of infertility; [2] Cod liver oil is used as a source of vitamin A and D, derived from liver of cod fish; Anterior pituitary is a source of pituitary gonadotropins that used in treatment of infertility; Blood of animals is used in preparation of vaccines and Heparin which is commonly extracted from porcine intestinal mucosa or bovine lung $[6,7]$.

Minerals: Minerals are metals or non-metals which are found from the earth could be used to treat inorganic mineral deficiencies or other problems in animals. Mineral salts are usually used in clinical practices, for instance ferrous sulphate is used to treat anemia, Magnesium sulphate is used as purgative used to relieve constipation, Magnesium trisilicate and Aluminium hydroxide are used as an antacid and Iodine is antiseptic. Iodine supplements are also used to treat Iodine deficiency [2].

Synthetic or semi-synthetic drugs: Synthetic or semi-synthetic drugs are evolved from application of science and technology in the laboratory. Semi-synthetic drugs are naturally occurring substances that have been chemically altered in the laboratory. Examples of synthetic or semi-synthetic drugs are sulphonamides, thiazide diuretics, apomorphine, and aspirin and so on. It is more preferable way since pure compounds can be easily obtained and structural modifications to produce potentially more active and safer drugs could be easily prepared [2,7].

Engineered drugs: Genetic engineering is the newest area of drug development. It involves cleavage of DNA by enzyme restriction endonucleases. The desired gene is coupled to rapidly replicating DNA (viral, bacterial or plasmid). The new genetic combination is inserted into the bacterial cultures which allow production of vast amount of genetic material (drug). The processing of engineered drugs has used to get huge amounts of drugs, Drug can be obtained in pure form and it is less antigenic character. However contrary well equipped laboratory and trained manpower are needed and it is not as such simple. Examples insulin, growth hormone and erythropoietin are nowadays synthesized by genetic engineering techniques [6,7].

\section{Veterinary drug development}

Any drug development process must proceed through several 
stages in order to produce a product that is safe, efficacious and has to pass all regulatory requirements. The process of drug development starts with understanding of the disease and target identification and validation of the promising drug, which will be followed by the synthesis of novel chemical compounds such as lead compound $[2,6]$.

Although each company has its own internal organizational structure and approach to commercialization, in general there are three distinct research phases. The initial phase is the discovery phase, next is the development phase, and third is registration phase [8].

Discovery phase: This phase is cover when a novel entity is identified. The company will first conduct a marketing assessment to identify unmet animal health needs that can be addressed and that will result in a satisfactory return on investment. This assessment will guide scientists seeking novel chemistry, new antigens or other innovative technology [9]. The chemistry laboratory synthesizes a variety of similar molecules or analogs, or may provide fermentation derived materials, which are evaluated by screening against key targets of interest. This process determines structure activity relationships, in order to find a lead candidate. Sometimes, Preliminary adsorption distribution, metabolism, excretion Studies may also be used. Typically, The checklist For innovation will include considerations for intellectual property i.e., patentability, ease of manufacture, initial proof of concept studies in vitro and in vivo, active pharmaceutical ingredient stability, animal safety and preliminary toxicology studies. The discovery and preclinical studies are not typically conducted under good laboratory practice requirements [9].

Development phase: When additional information is generated to decide whether the drug should proceed to the registration phase, which is when studies are conducted to satisfy the quality, safety and effectiveness approval criteria of regulatory agencies Should a company choose to pursue the novel chemistry or technology on the basis of the initial evaluations, additional studies are conducted to further characterize the behavior of the drug substance. Preliminary evaluations regarding where and how to manufacture the potential product are performed. Additional information on the market assessment and other business considerations are also gathered. An internal business decision to advance the candidate to the more expensive registration phase studies may be made. The drug sponsor will contact the College of Veterinary Medicine and open an investigational new animal drug file, which officially begins the drug approval process $[8,9]$.

Registration phase: This phase begins when studies, which have generally been agreed upon by the College of veterinary medicine, are conducted under good clinical practice, good manufacturing practice requirements. All data collected during these studies are used for the purpose of gathering information to fulfill the requirements of the new animal drug application [9].

\section{Tests for veterinary drug development}

Generally, for drug development two tests are conducted:

Preclinical testing: It can be done on laboratory animals or cell culture that yields information on the biological effects of new substance. For this test use as few animals as possible will ensures that their human and proper care, use two or more species like one rodent and one non-rodent are tested because a drug may affect one species differently from another. Animal testing is used to know, how much of a drug is absorbed into the blood, how it is broken down chemically in the body, the toxicity of the drug and its breakdown products (metabolites), how quickly the drug and its metabolites are excreted from the body [4].

Clinical test: The clinical development of new drug usually takes place in steps or phases conventionally described as clinical pharmacology (Phase I), clinical investigation (Phase II), clinical trials (Phase III) and post-marketing studies (Phase IV) [2].

Phase I studies on healthy subjects (20 to 80 ) and seek to determine whether effects observed in laboratory animals experiments also occur in other animals or humans [7].

Phase II here potential drugs are tested on selected patients for therapeutic efficacy in those disease states for which they are intended [7].

Phase III is entered, involving a larger group of patients in whom the new drug will be compared with standard treatments in terms of therapeutic outcome [2].

Phase IV is monitoring the drug after market authorization from the regulatory body as it is used in the larger population to catch any unexpected serious adverse effects [2,7]. The drug development process described above more applies for drugs used in human medicine, for veterinary agents the process is similar but with a few notable exceptions. Since preclinical and Phase I studies are on animals, processes are generally shorter for veterinary drugs. Safety and efficacy must be confirmed for each species included on the label in brand or generic medications and in new dosage forms. Veterinary dosage forms are generally more diverse and complex to address differences within and among species; weight differences between species may reach up to 700 fold [3].

\section{Challenges in drug discovery}

Drug discovery is a slow process (it may take 10 or more years), requires big investment (costy) it require a billions of dollars and Uncertain (One cannot be sure even after a very long process and investments). Only one in 10,000 compounds ever reach the market [7]. Possible solutions to the Challenges in drug discovery are Use available drugs properly, Provide priority for disease prevention and eradication programs through proper husbandry, nutrition and vaccination and conducting research on identifying problems and searching solutions [2].

\section{Safety, quality and efficacy of veterinary drugs}

Safety is interpreted widely, to include the animal being treated and in-contact animals; the user, including the veterinarian, farmer or pet owner administering the medicine; the consumer of livestock products from treated animals; and the environment [10,11].

Quality means that medicines must be manufactured with appropriate quality control procedures, in premises that are inspected and licensed; the ingredients must be of appropriate purity, in the correct proportions and correctly processed; the containers must be robust with secure closures; and the labeling must be accurate and informative [10,11].

Efficacy means that the medicines must be effective against the 
diseases, in the species of animals, at the dose rate, frequency and duration of treatment, and by the route of administration claimed by the manufacturer $[10,11]$.

\section{Rational use of veterinary drugs}

Rational use of drugs in veterinary science is defined as that sick animal should receive medications appropriate to their clinical needs, in doses that meet their own individual requirements, for an adequate period of time, and at the lowest cost to them [12]. These requirements will be fulfilled if the process of prescribing is appropriately followed. This includes: steps in defining patients' problems or diagnosis; in defining effective and safe treatments (drugs and non-drugs); in selecting appropriate drugs, dosage and duration; in writing a prescription; in giving patients adequate information; in planning to evaluate treatment responses [13]. The provision of successful animal health service requires the availability of safe, effective, quality and affordable drugs of the required quantity at all times. Many diseases that cause mortality or morbidity can be prevented or treated by drugs [4].

The number of drugs used is increasing nowadays with: Change in husbandry system, Increase in the price of animals and Presence of improved and more susceptible breeds. The available drugs must be prescribed, presented, dispensed and used rationally [4]. Proper utilization of veterinary drugs involves handling, prescribing, dispensing, delivery of drugs for animals, under proper supervision and involvement of veterinary professionals. Rational use of veterinary drugs is a complex issue demanding mainly an integrated action of prescribers, dispenser, livestock owners and the general public, animal health administrators, veterinary drug and feed administration and control authority, research and educational institutes, policy makers, legal affairs and police [2].

To improve rational drug use the following measures could be taken:

- $\quad$ Proper diagnosis and selection of the drug which is effective, convenient and safe,

- Accurate and complete prescription and dispensing of drugs,

- Informing owners on side effects, adverse drug reactions, dosage schedule and risk of withdrawing the therapy.

- Improve professionals and communities skill and knowledge via trainings, discussion forum, banner, poster, pamphlets, newsletters both in public and private sectors,

- Enhance availability and proper supply of drugs,

- Appropriate rule and regulation and proper implementation and

- $\quad$ Process of drug development [2,5].

\section{Irrational veterinary drug use}

Many researchers have highlighted the incidence and prevalence of irrational drug use in developing countries. irrational drug use results decreases drug's efficacy, promote the development of drug resistance, they may harm the animal itself as drugs are potential poisons and it is also a threat to human health from residue and human medicine from co-or cross-resistance point of views [14]. Irrational drug use, the use of drugs when no therapy is indicated, use of wrong drugs for specific conditions (incorrect diagnosis), incorrect route of administration, dosage, or duration, the storage of drugs with other materials, absence of refrigerators for drugs that need cold chain, poor labeling of the dispensed items, lack of animal owner counseling, incomplete compiling and recording of prescriptions and charging owner unreasonably high prices [5].

\section{Veterinary drugs dispensing practice}

Dispensing refers to the process of preparing veterinary drugs and distributing to users with provision of appropriate information, counseling and follow up. It may be based on a prescription or an oral request of owner depending on the type of veterinary drugs to be dispensed. Good dispensing practice ensures that the correct veterinary drug is delivered to the right animal patient, in the required dosage and quantities, with clear instructions [2].

This process may take place in the animal health institutions and community veterinary drug retail outlets. It is often carried out by veterinary drug professionals. Any error or failure in the dispensing process can seriously affect the care of the animal patient mainly with medical and economical consequences and public health hazard. Therefore, the dispenser plays a crucial role in the therapeutic process. The quality of dispensing may be determined by the training and supervision in which the dispenser has received and the veterinary drug information available to the dispenser [20]. Veterinary drug dispensers must have knowledge about the veterinary drugs being dispensed about: common use, correct dose, precautions about the method of use, common side effects, common interaction with other medicines or feed, storage needs, good calculation and arithmetic skills and, must have ability to explain information clearly by the language the owner can understand and check whether the information is being understood [15].

Before owners arrival the dispenser should prepare him/her self and the dispensing environment and facilities. check the dispensing room, shelves and dispensing desk are clean and organized, wear a clean and white gown, attach your identification tag on the gown in such a way that it is visible to clients, check availability of dispensing aids such as labeling materials, packaging materials, sufficient numbers of spoons etc and ensure availability of updated national veterinary drug list, rational use of veterinary drugs manual, standard veterinary treatment guideline, veterinary formulary, and prescription registration book [2].

Dispensing environment: Dispensing environment must be clean, because most medicinal products are for internal use. The environment must also be organized so that dispensing can be performed accurately and efficiently. The dispensing environment includes staff, physical surroundings, and shelf and storage areas, surfaces used during work and equipments and packaging materials $[16,17]$. It should also possess: optimum temperature, sufficient lighting but not direct sun light, optimum humidity, cold storage facilities, adequate number of shelves and suitably spaced to permit cleaning and inspection, a dispensing bench of adequate size having a smooth, impervious working surface, lockable cabinet for narcotic drugs, psychotropic substances and poisons, owner waiting area and dispensing aids [15]. 
Dispensing procedures: The development and use of written standard operating procedures for dispensing process will improve consistency and quality of work. The framework for such standard operating procedure may be based on the five major steps to be performed in the dispensing cycle during the dispensing process [15].

Step 1: Receive and validate prescription or verbal request: Upon receiving a prescription, the dispenser should confirm the name of the owner and the identity of the patient animal. This action is particularly important when the clinic is dealing with a large crowd of animals and when there is any risk that the dispenser may mix up prescriptions. Cross checking the name of the owner and identifications of the animal must also be done when issuing the drugs [5].

Step 2: understand and interpret prescription (oral request): carefully read the prescription or validate verbal request, check if the prescription is legally and currently written, interpret any abbreviations used by the prescriber correctly, confirm that the doses prescribed are in the normal range for the animal patient considering species, sex, body weight and age, identify common drug interaction, verify inadequately written prescription and make necessary correction with the prescriber's consent, perform any calculations of dose and the quantity to be issued correctly [3].

Step 3: Prepare items for administration or issue: preparation of items for administration and/or issue is the central part of the dispensing process. Select stock container by reading the label and cross matching the drug name and strength against the prescription. The dispenser should check the stock to make sure that it is not expired and choose the oldest stock. Read the container label at least twice during the dispensing process. Do not select the prescribed drugs according to the color or location of container. Do not open many stock of containers at the same time. This trend will lead to errors and/or expose the drugs to air and eventually leads to deterioration in quality [4].

While counting, pouring or measuring, the following points should be noted; under and/or over measuring or counting should be avoided, clean and sterilized syringe and needle, graduated measuring cylinder and/or flask must be used for measuring liquid reduction. If small volume is to be measured, small measuring cylinder or flask has to be used and appropriate weight measuring balance should be used in dispensing liquid formulations: must be measured in a clean vessel and should be poured from the stock bottle with the label kept up ward. This avoids damage to the label by any spilled or dripping liquid. Pour the measured liquid preparation into the container/bottle and label it. Do not use owners own bottle [2]. in dispensing solid formulations: do not use fingers to count tablets or boluses as this can lead to contamination of drugs, count and put them in a labeled drug container or pack, close stock containers tightly after dispensing and keep the spoon or other counting materials clean at all times [15].

Step 4: Recording, documentation and reporting: Records of issues to animal patients are essential in an efficiently run dispensary, such records can be used to verify the stocks used in dispensing, and they will be required if a need arises to trace any problems with veterinary drugs issued to patients [11].

There are three different methods that can be used to keep a record of drugs dispensed. These are: When a prescription is retained, the dispensing staff should put initials and annotate the prescription and either files or enters the details into a record book. And when the prescription is returned to the owner of animal patient details of the drugs dispensed must be entered into a record book before the items are issued to the patient [18]. When computers are used in the dispensing process the computer program should retain the information, which can be recalled to generate summary report [11].

The following information should be included into the record book and/or computer: the date, name of the owner, and the animal patient's identity (name, identication number, species, sex, age). Plus the drug name, dosage strength and dosage form, and the amount issued [11]. The dispenser name and initials the receipts for requisition, receiving as well as the prescription registration book should be kept properly, filled prescriptions should also be kept as a receipt. Regular reports on drug consumption and prescribing pattern from patient prescription registration book should be prepared and report to the concerned veterinary drug authority timely [3].

Step 5: administer or issue drugs to animal patient/owner with clear instructions and advice for drugs to be administered at the veterinary establishments, the owners should be informed about withdrawal period for milk, meat, egg and honey and not to interrupt treatment when side effects occur or in the absence of response without consulting the prescriber or dispenser [15]. In addition to these for prepared, packaged and labeled drugs issued to owners the following written information should also be provided: [15].

- How much and how often to give the drug,

- How long the treatment is to last How to give the drug,

- How to store the drug,

- Not to share drugs to other animals,

- To keep drugs out of reach of children and

- Finally, check whether the owners have understood the information provided [11,15].

\section{Transportation of veterinary drugs}

When transporting veterinary drugs in vehicles; it must be stored properly to prevent damage or spillage; it must be transported in section of the vehicle separated from the driver, other passengers, animals or food. They should be transported in accordance with any product guidance, secured against theft and unauthorized access, and accompanied by relevant information about the products. The product should not contaminate and is not contaminated by other products and appropriate environmental conditions must be maintained by using cold chain for thermo labile products $[16,17]$. Transportation and storage of veterinary products containing hazardous substances, such as toxic, radioactive material, and other dangerous pharmaceutical products presenting special risks of abuse, fire or explosion, should be stored in safe and secure areas, and should be transported in safe, suitably designed, secured containers and vehicles, for Example, Combustible or flammable liquids, solids and pressurized gases [2].

\section{Stock management}

Good stock management facilitates safe and effective dispensing service to ensure proper stock management the following elements 


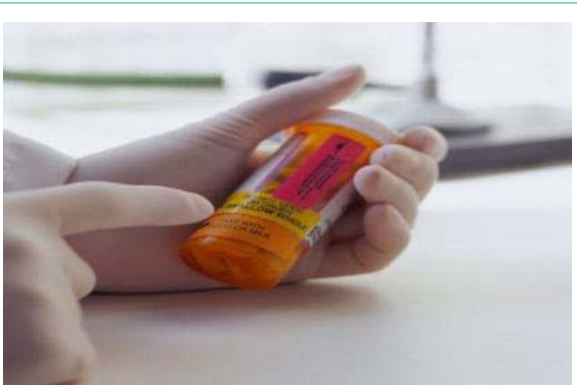

Figure 1: Source: [20].

are important: acquisition of medicines, stock keeping, and stock rotation, arrangement of veterinary drugs in the dispensary and storage conditions [15]. Before veterinary drugs and medical supplies are issued from store to dispensing room, store requisition (delivery issue) form should be filled by the dispenser and duly signed by authorized personnel. It is mandatory that all veterinary drugs are obtained from legal sources [6].

When you receive veterinary drugs for dispensing: ensure that there is sufficient storage place, prepare and clean the storage areas, inspect packages for damaged and/or expired products, check that al original boxes, tins, or bottles are unopened and are in good condition [3]. If products are defective: separate the damaged or expired stock from the usable stock, refuse to accept the products and note the problem on the delivery note, follow your facility's procedure for handling damaged or expired stock. Report quality problem to the nearest regulatory body and fill prepaid adverse drug event report form and send to regulatory body [2] (Figure 1).

If products are not damaged fill issue voucher and requisition voucher, count the number of units for each product received and compares to issue voucher, record received item on receiving voucher, stock card, bin card and computer, ensure the expiry date is visibly marked on every package or unit, arrange products in the storage area in such a way to facilitate the dispensing of the first to expire by first expiry first out or first in first out procedure. Separate damaged, expired and returned products from the usable stock without delay and dispose using established disposal procedures and report to the appropriate body for redistribution of veterinary drugs with nearer expiry date $[2,15]$.

Quality assurance of veterinary drugs in the stock: For quality assurance of veterinary drugs we can use different methods. The tests used for quality assurance may be classified in to simplified tests which are basic tests or sophisticated analytical examination. Because sophisticated analytical examinations require special skills and well equipped laboratories, simplified tests are commonly used in dispensaries for verifying the quality of dispensed veterinary drugs. Such tests may usually serve to ascertain the absence of gross degradation, absence of contamination or absence of damage [3]. When a product fails the basic tests, it should not be used until its quality is established by analytical examination. It is important to note that the shelf-life of veterinary drugs may be markedly shortened by improper storage conditions. Therefore, the expiry date information of a veterinary drug product may not guarantee the quality of it. Any quality problem of veterinary drug product should be reported to the concerned body immediately by adverse event report form [2] (Table 2).

Stock rotation: When using products, it is important to follow the first expire first out and first in first out procedure, which minimize wastage due to product expiry. Therefore: periodic stock reconciliation should be performed by comparing the actual and recorded stocks [19]. Always issue products that will expire first, ensuring they are not too close to or past their expiration date. to facilitate first expire first out and, first in first out place products that may expire first in front of products with a latter expiry date. Write expiry dates on stock cards, so that stocks can be used before they expire. Supplies with no expiry or manufacture date, for example; gauze, cotton etc. should be stored in the order received and dispensed accordingly [3] (Figure 2).

\begin{tabular}{|c|c|c|c|}
\hline$S / n$ & Common Quality problems & & Common Problem Indicators \\
\hline 1 & All products & $\bullet$ & Broken packaging \\
\hline \multirow{2}{*}{2} & \multirow{2}{*}{ Liquid products } & $\bullet$ & Discoloration, cloudiness, sediment, broken seal on bottle \\
\hline & & $\bullet$ & Cracks in ampoule, bottle or vial, moistures in the packaging, leakage \\
\hline 4 & Latex products & $\bullet$ & Dry, brittle or cracked \\
\hline \multirow{2}{*}{5} & \multirow{2}{*}{ Lubricated latex products } & $\bullet$ & Sticky packaging, stained packaging, discolored products \\
\hline & & $\bullet$ & or lubricant, leakage of the lubricant \\
\hline \multirow{2}{*}{6} & \multirow{2}{*}{ Tablets or bolus } & $\bullet$ & Discoloration, missing boluses, unusual smell \\
\hline & & $\bullet$ & Stickiness, especially coated tablets \\
\hline \multirow{3}{*}{7} & \multirow{3}{*}{ Injectable } & $\bullet$ & Torn or ripped packaging, missing parts, broken or bent parts \\
\hline & & $\bullet$ & Moisture inside the packaging or stained packaging \\
\hline & & $\bullet$ & Particle matter \\
\hline 8 & Chemical Reagents & $\bullet$ & Discoloration \\
\hline
\end{tabular}

Note: S/N stands of serial numbers Source: [2] [20] [30]. 


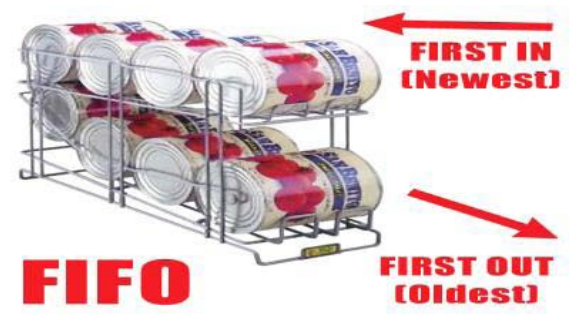

Figure 2: Source: [29].

Note: FIFO stands for first in first out.

Arrangement of veterinary drugs: Veterinary drugs should be arranged on shelves made of steel or treated wood and the shelves should be strong and robust $[2,6,15]$. Animal health institutions and veterinary drugs retail outlets can use one or a combination of the following commonly used methods of veterinary drugs arrangement: Pharmacotherapeutic category, Alphabetical order by generic name and dosage forms [15].

In arranging veterinary drugs, the following points should be considered: Each dosage form of veterinary drug is arranged in separate and distinct areas, sufficient empty space should demarcate one veterinary drug or dosage form from another [6].

\section{Storage conditions}

The veterinary drugs used to treat export livestock must be stored in accordance with the manufacturer's recommendations [1].

\section{Storage conditions can be arranged in two classes:}

Normal storage conditions: It's Storage in dry, well-ventilated premises at temperatures of $15-25{ }^{\circ} \mathrm{C}$ or, depending on climatic conditions, up to $30{ }^{\circ} \mathrm{C}$. Extraneous odor, other indications of contamination, and intense light must be excluded [2]. Veterinary drugs that must be stored under defined conditions require appropriate storage instructions. Deviation may be tolerated only during shortterm interruptions, for example, during local transportation unless otherwise specifically stated, for instances continuous maintenance of cold storage. Unless special storage conditions are stated, it is vital that veterinary drugs be stored in a dry, adequately ventilated shady and cool store room. Efforts should be made to maintain the specified storage conditions with regard to exposure to humidity, sun light, and heat, and so on [3].

- To reduce the effects of humidity: by opening windows, using fans or air conditioners and hygrometer to regulate humidity.

- To protect products from sunlight for photosensitive substance; Shade the windows or use curtains, Keep products in intact cartoon, do not store or pack products in sunlight and Maintain trees

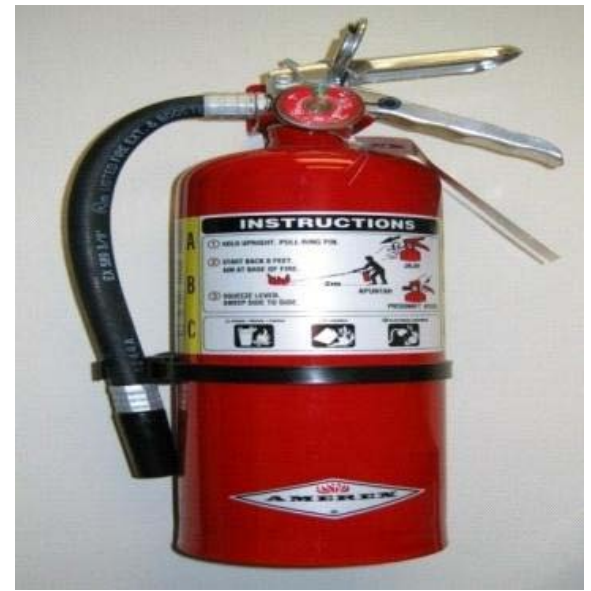

Figure 3: Source: [30].

on the premises around the facility.

- To protect products from heat for heat sensitive substance; It is important to have thermometers in order to regulate the temperature [6].

Special storage conditions: Special storage conditions which can be further classified in two three as cold storage conditions, combustible or flammable storage conditions, secured storage [15].

Cold storage conditions: Cold storage conditions maintained by using refrigerators and freezers for products that may be degraded rapidly when kept at room temperature, like vaccines and insulin [2]. When using refrigerators and freezers: Refrigerators that open on the top are more efficient than vertical ones, because hot rises while cold air falls, Store products that are sensitive to freezing or very low temperatures on the upper shelves. If there is enough space, place a few plastic bottles of water in the refrigerator. This will help maintain the temperature for a longer period of time if the power is cut off. Do not keep staff food in the refrigerator [1]. Opening and closing the door may lower the temperature and cause veterinary drugs to deteriorate. Record the temperature daily. Check that there is enough space around the refrigerator so air can move freely [19] (Table 3).

Combustible (Flammable): Combustibles such as alcohol, ether and other organic solvents must be stored in special or separate rooms, since it virtually guarantees that fire will not spread throughout the store. All stores should be equipped with fire extinguishers. A good alternative to fire extinguishers is represented by wooden or metal buckets filled with sand [2] (Figure 3).

Secured storage conditions: Narcotic drugs, psychotropic

Table 3: Terms That Relate To Storage Temperature.

\begin{tabular}{|c|l|l|}
\hline S/n & \multicolumn{1}{|c|}{ Terms used } & \\
\hline 1 & Store frozen (deep freezing $)-20^{\circ} \mathrm{C}\left(4^{\circ} \mathrm{F}\right)$ & For products such as certain vaccines, need to be transported within a cold chain \\
\hline 2 & Store at $0^{\circ} \mathrm{C}\left(-4^{\circ} \mathrm{F}\right)$ & For product labeled store at Refrigerator temperature \\
\hline 3 & Store at $2-8^{\circ} \mathrm{C}\left(36-46^{\circ} \mathrm{F}\right)$ & For products which are very heat sensitive but must not be frozen. \\
\hline 4 & Keep cool & To be kept between $8-15^{\circ} \mathrm{C}\left(45-59^{\circ} \mathrm{F}\right)$ \\
\hline 5 & Store at room temperature & For product labeled to be kept between $8-15^{\circ} \mathrm{C}\left(45-59^{\circ} \mathrm{F}\right)$ \\
\hline
\end{tabular}

Note: S/n stands for serial numbers, Source: [19]. 


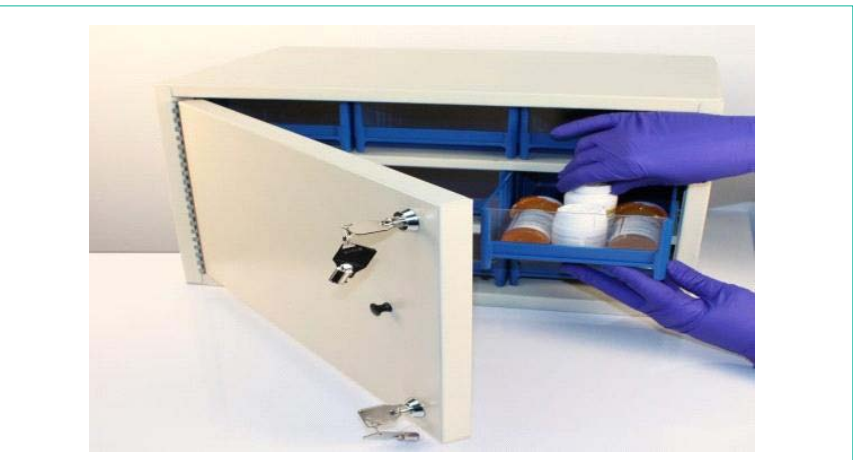

Figure 4: Source: [19]

substances, and their documents should be kept in securely locked rooms or cupboards. The keys should be kept in a secure place and it is preferable that only the chief of pharmacy should have access to them [2] (Figure 4).

\section{Principles of rational prescribing}

Good prescribing practice is prescribing the right veterinary drug for the right patient, in the right dosage of the right formulation and for the right length of time. Good prescribing practice also includes not prescribing any veterinary drug at all if it is not needed. it requires detailed knowledge of the patho-physiology of the diseases and clinical pharmacology of the veterinary drugs [3]. The use of international non proprietary names or generic names of veterinary drugs in prescribing is an essential component of good prescribing practice. This is because generic veterinary drugs are less costly, and for a by generic prescription any suitable product can be dispensed hence avoiding delay while looking for a specific brand [2].

\section{Good prescribing practice needs:}

A) Assessment of the benefit-to-risk and/or benefit-to-cost ratio of prescribing

During prescription, professionals should consider the following assessment tools: seriousness of the problem to be treated, appropriateness for the animal and optimal use of the veterinary drug with respect to: the safety, efficacy and quality of the veterinary drug, possible contraindications example, albendazole should not be given during early pregnancy due to the possibility of embryo toxicity, drug to drug interactions example, oxytetracycline should not be given together with $\mathrm{di} /$ trivalent cautions such as $\mathrm{ca}+2, \mathrm{mg}+2$, al +3 or $\mathrm{fe}+2$ due to the chelating behavior of oxytetracycline with these cautions, drug-feed interactions. Example: fatty meals facilitate the absorption of albendazole where as full rumen may impair its absorption and treatment history $[2,15]$.

\section{B) Public health significance}

The effect of the drug on consumers of products from treated animals. Example: Nowadays, chloramphenicol is banned from use in food-producing animals because of its high risk in human from consumption of products from treated animals [18].

\section{C) The cost of veterinary drug}

The cost of the drug should be reasonable. Example: treatment of chronic bovine tuberculosis by isozanaide is not advised because of its high cost to benefit ratio $[15,18]$.

\section{D) justification for veterinary drug therapy}

One has to justify the need for treatment before prescribing. The professionals should avoid unjustifiable prescription. Example: prescribing of broad spectrum antibiotics for all animal patients with coughing, prescription of drugs based on the owners interest $[2,6]$.

\section{E) selection of appropriate drug}

Once treatment is justified, to decide which particular veterinary drug to use, the prescriber should go through the process of: selecting the therapeutic class; example: antibiotics for infection, selecting group of veterinary drugs within the class and selecting a particular medicine in the group; example: streptomycin among aminoglycosides. The choice of drugs should also consider; sensitivities, site of infection, feature of animal patients such as contraindications, availability of the drug, pharmacokinetics and pharmacodynamic properties [2].

\section{F) Route of administration}

Choice of route of administration of drugs depends on site of desired action systemic or local; physical and chemical property of the drug and its formulation solid, liquid, gas, solubility, ph, irritancy; the rapidity with which the response is desired which is fast action, intravenous; patient's condition just unconscious, vomiting; the ability of the drug to withstand the conditions of the gastrointestinal tract example: insulin cannot be administered orally since it is degraded in the gastrointestinal tract. Example: intravenous route is preferable for severe infections such as milk fever and cowdriosis $[2,20]$.

\section{G) Dosage and course of treatment}

The dosage of the drug and course of treatment may vary with characteristics of the patient body weight, age, species, physiological status and pathology; the nature of the disease that means chronic or acute; and type and strength of the drug. Example 1: A single dose of diaminazine aceturate is given for the treatment of bovine trypanosomosis but oxytetracycline $10 \%$ is given from 3 to 5 days for treatment of pneumonic pasteurellosis. Example 2: A single dose of oxytetracycline $20 \%$ is enough for the treatment of pneumonic pasteurellosis but oxytetracycline $10 \%$ is given from 3 to 5 days $[2,6,19]$.

Prescription processes: There are six major steps to be followed in the prescribing process

Step 1: Defining the diagnosis, the first step in rational treatment is defining the patient's problem, which is making a correct diagnosis. To conduct correct diagnosis it should be supported by laboratory procedures in addition to physical examination techniques [21].

Step 2: Specifying the therapeutic objectives, once a diagnosis is made, one has to specify his or her therapeutic objective, what the prescriber wants to achieve with treatment to be applied, to cure an infectious disease, or to relief animals from non-infectious disease like bloat. the better you define your therapeutic objective, the easier it is to select the suitable veterinary drug [21].

Step 3: Selecting the suitable veterinary drugs, select veterinary 
Table 4: Techniques to avoid confusion in writing figures or units.

\begin{tabular}{|c|c|}
\hline Incorrect way of writing & Correct way of writing \\
\hline $.5 \mathrm{mg}$ & $0.5 \mathrm{mg}$ \\
\hline $\mathrm{Mg}$ & Mcg \\
\hline $1.0 \mathrm{mg}$ & $1 \mathrm{mg}$ \\
\hline 500000 & 500,000 \\
\hline $0.025 \mathrm{~g}$ & $25 \mathrm{mg}$ \\
\hline
\end{tabular}

Source: [19] [20].

drugs as described above. Selected veterinary drugs are the veterinary drugs you have chosen to prescribe regularly, and with which you have become familiar with their therapeutic effects and side effects [15].

Step 4: Prescription writing, a prescription is a written order of the prescriber for one or more medication, and instructs the dispenser how to prepare and dispense veterinary drugs and the owner how to use them. prescription should be written on a standard prescription paper, written in ink, legible, written in generics, clear (not ambiguous), written in English with some Latin abbreviations, and the quantity of ingredients should be expressed in metric system [22] (Table 4).

\section{Veterinary prescription paper: (Figure 5)}

Step 5: Give information, instructions and warnings, most owners do not give the prescribed drugs correctly to patient animals; give them irregularly, or not at all. the most common reasons are, symptoms have ceased, side effects have occurred, the drug is not perceived as effective, or the dosage schedule is complicated for owners for example drugs with a short half-life or a narrow therapeutic margin may become ineffective or toxic if taken irregularly [2] Patient adherence to treatment can be improved in three ways: prescribe a well chosen drug treatment; create a good veterinarianowner relationship; and take time to give the necessary information, instructions and warnings [22].
The six points listed below summarize the minimum information that should be given to the owner:

- $\quad$ Effects of the drug: which symptoms will disappear; and when; how important is it to give the drug; what happens if it is not given.

- $\quad$ Side effects: which side effects may occur; how to recognize them; how long will they remain; how serious they are; what to do if they occur.

- Instructions: when to give; how to give; how to store; how long to continue the treatment; what to do in case of problems [2].

- Warnings: it is what not to do; maximum dose; need to continue treatment.

- Next appointment: when to come back or not; when to come earlier; what to do with left-over drugs; what information will be needed.

- $\quad$ Everything understood; repeat the information; any more questions [21].

Step 6: Record keeping and Monitoring of the treatment: Information containing the date of prescription, the owner name, the animal patients name, species, sex, age, the disease diagnosed, the prescribed drug name, dosage strength and dosage form and amount, the prescriber name and initials should be recorded on the case book. The purpose of monitoring is to check whether the treatment has solved the patient's problem. You should use the same criteria for monitoring the effect, but in practice they can be condensed into two questions: is the treatment effective? And Are there any side effects? [6].

\section{Drug labeling}

Label means any written, pictorial or other descriptive material which gives information about the veterinary drugs including cartons, vials, and leaflets. All finished drug products available for market

Ser.No, _ 000000

\section{Veterin ary Prescription Paper}

Name and Level of Animal Health Institution

Address Region
Owner's Name Zone__own
Address Region

Figure 5: Source: [20] [30] 
should be identified by labeling at their primary and/or secondary packaging, as required by the national legislation, the labels should not be easily erased and/or detached [21].

The label bearings at least the information: the statement for animal treatment only or for veterinary use only, trade name, generic name, active ingredient and other substance added, withdrawal period, restriction to its use, batch number, storage instructions and handling precautions, directions for use such as dose rate, route, duration of treatment and frequency of application; adverse effects, cautions, contraindications, manufacturing date, expiry date, net contents with clear unit of measurement, the name and address of the manufacturer or the company or person responsible for placing the product on the market [22].

Any deviation from the label makes the information on the label invalid. Reading the label prior to using a product is extremely important. If the products dispensed by veterinary drug professional are not in the original labeled container must be labeled by him/her in the same manner that appears on the commercial label [2].

Off-label use: A drug is used off-label if it is used other than strictly in accordance with the manufacturer's label or product insert. With a few specific exceptions, it is not illegal to use a veterinary medicine or pesticide off-label. However, off-label use must be prescribed by a veterinarian, who assumes full responsibility [22]. Whilst it is generally important to follow the manufacturer's directions for use, there are occasions when off-label drug use is appropriate. Off-label treatment is often necessary for minor species, such as goats or buffalo, when there is no suitable drug registered for that species, so a product registered for sheep or cattle must be used instead. It may also be necessary to use a product off-label because the drug of choice is temporarily not available, and an alternative is required. Veterinary drugs should only be used off-label if there is no suitable product registered, or the only registered products are not available $[3,22]$.

Off-label uses that are banned include: using a veterinary medicine or pesticide registered for oral or external use as an injection;

- Using chloramphenicol, organochlorines, diethylstilboestrol or nitrofuran antibacterials to treat livestock.

- Using sulphonamide antibacterials, except for sulphadiazine, sulphadimidine, sulphadoxine, sulphaquinoxaline or sulphatroxazole to treat livestock.

- Using arsenical compounds as an external livestock treatment.

- Using hormonal growth promotants other than precisely in accordance with label directions; or the use of a product in any manner if the manufacturer's label specifically states that the product is not to be used in that manner [3].

\section{Packaging}

Packaging may be defined as different components which surround the pharmaceutical product from the time of production until its use for instance bottle, vial, closure, cap, ampoule, and blister. The packaging of a pharmaceutical product is aimed at ensuring that veterinary medicines arrive safely in the hands of users. The packaging must protect the product against all adverse external influences that may affect its quality or potency, such as light, moisture, oxygen, biological contamination and mechanical damage. The packaging itself should not have an adverse effect on the product example, through chemical reactions, leaching of packaging materials or absorption); the product should not also have an adverse effect on the packaging, changing its properties or affecting its protective function $[2,19]$.

Packaging may be classified as primary or secondary: primary container is in physical contact with the veterinary drug (for example, bottle, blister pack, tube, syringe), whereas secondary packaging is the immediate packaging around the primary container (for example, carton, and leaflets/inserts) [3]. The choice of primary and/or secondary packaging materials depends on the degree of protection required, compatibility with the contents, the filling method and cost, and the convenience of the packaging for the user (e.g. size, weight, method of opening/reclosing, legibility of printing). Both single-dose and multi-dose containers also exist [3].

Re-packaging: Re-packaging is the process by which the veterinary drug professionals transfer a medication manually, or by means of an automated system, from a manufacturer's original commercial container to another type of container in advance. Because original containers may contain large amount of drugs, repackaging of drugs into another container may be necessary in order to dispense drugs for animal patient owners. Such repackaging procedure can be done at the spot or in advance [1]. The following guidelines are recommended in re-packaging of drugs: re-packaging procedures must comply with laws and regulations. The re-packaging operations and area must be clean and separate. Only one drug product at a time should be repackaged in a specific work area $[20,21]$. Before beginning a repackaging run, a physical evaluation of the drug product should be made to assure product integrity (color, odor, appearance, and markings). The bulk container should also be examined for evidence of damage, contamination, and other deleterious effects [1].

All repackaging equipment and systems should be operated and used in accordance with the manufacturer's or other established instructions. Upon completion of repackaging, all unused drug stock, unused labels and finished packages should be removed from the repackaging area. The packaging equipment should then be completely emptied, cleaned, and inspected before commencing the next repackaging operation [3].

Packaging aids and materials: The materials used for repackaging include: glass bottles, plastic bottles, collapsible tubes, paper envelops, and plastic envelops. Paper has the least value as the primary packaging material in terms of maintaining the quality, safety and stability of packaged drugs [1] (Table 5).

\section{Systems of measurements}

There are three systems of measurements namely: 1) metric, 2) apothecary and 3) household systems. [2]

Metric system: Metric system is the most commonly used system and sometimes termed as International system unit. This is because of the simplicity of the decimal system, the clarity provided by the base units and prefixes of the SI, and the ease of scientific and professional communications through the use of a standardized and internationally accepted system of weights and other measurements. 
Table 5: The requirements of containers for packaging different dosage forms are indicate.

\begin{tabular}{|l|l|l|}
\hline \multicolumn{1}{|c|}{ Package characteristics } & \multicolumn{1}{|c|}{ Examples } \\
\hline Tablets/capsules & \multicolumn{1}{|c|}{$\begin{array}{l}\text { Clean, dry, plastic or glass container with } \\
\text { tightly sealing cap or seal }\end{array}$} & Blister packages, plastic sachets, tightly sealing plastic or glass containers with screw or snap cap \\
\hline Desirable & $\begin{array}{l}\text { Clean, dry container that provides } \\
\text { protection from dirt and moisture }\end{array}$ & zip-lock plastic bags, glycine paper, hinged-lid unsealed boxes, sifter-top boxes, tight-top tins \\
\hline Acceptable & $\begin{array}{l}\text { Unclean absorbent paper, cotton, } \\
\text { cardboard containers with no provision for } \\
\text { closure }\end{array}$ & Unsealed plastic bags, paper bags, newspaper or other printed paper \\
\hline Undesirable & $\begin{array}{l}\text { Clean, dry, light-resistant glass container } \\
\text { with tightly sealing cap }\end{array}$ & Amber or opaque bottle with screw cap \\
\hline Liquids (oral and topical) & $\begin{array}{l}\text { Clean, dry plastic or glass container with } \\
\text { tight-fitting cap }\end{array}$ & Glass or plastic bottle with tight-fitting cap \\
\hline Desirable & Unclean paper, cardboard, metallic & Previously used liquid-containing cartons, plastic-lined paper bags, plastic bags \\
\hline Acceptable & &
\end{tabular}

Source: [19].

The system is used to manufacture and label pharmaceutical products for prescription and administration of drugs [19]. The system has one primary (base) unit and set of prefixes. Base units are meter (length), liter (volume) and gram (weight) [6].

Sometimes international unit is also included in metric system. The international unit is a unit of measurement for the amount of a substance which is based on the measured biological activity or effect. There is an international agreement specifying the biological effect expected with a dose of one IU. The unit is used for vitamins, hormones, some medications, vaccines, blood products, and similar biologically active substances. One IU of insulin is the biological equivalent of about $45.5 \mu \mathrm{g}$ pure crystalline insulin (1/22 mg exactly). $1 \mathrm{IU}$ of vitamin A is the biological equivalent of $0.3 \mu \mathrm{g}$ retinol, or of $0.6 \mu \mathrm{g}$ beta-carotene. One IU of vitamin C is $50 \mu \mathrm{g} \mathrm{L}$-ascorbic acid; one IU is the biological equivalent of $0.025 \mu \mathrm{g}$ cholecalciferol (ergocalciferol). One IU is the biological equivalent of about 0.667 $\mathrm{mg}$ d-alpha-tocopherol (2/3 mg exactly), or of $1 \mathrm{mg}$ of dl-alphatocopherol acetate. One IU represents 0.6 microgram of a standard preparation of penicillin $[2,19]$.

Apothecary system: Apothecary system is an old system of measurement and used first by apothecaries (early pharmacists). It is not commonly used. However, some countries like US are still used it. It has units for weight and volume only [2].

Apothecary systems of measurements:

- Grain (gr) is the basic unit of weight in apothecary system $1 \mathrm{gr}=60 \mathrm{mg}=0.06 \mathrm{~g}$,

- Dram is the basic unit of volume in apothecary system,

- $\quad$ Ounce $(\mathrm{oz})$ is the common unit of volume in apothecary system and

- $\quad$ Pound (lb) =A unit of weight equal to 12 ounce, $1 \mathrm{~kg}=2.2 \mathrm{lb}$ [19].

Household system: The house hold system is derived from apothecary system. The units of house hold system are drop, teaspoon, tablespoon, cup, gallon and so on.

Approximate equivalents to household measure:

1 teaspoon $(\mathrm{tsp})=60 \mathrm{drops}=5 \mathrm{ml} 1$ tablespoon $(\mathrm{tbsp})=15 \mathrm{ml}=$ 3 teaspoon
1 glass $=1$ cup $=250 \mathrm{ml} 1$ ounce $=2$ tablespoon $=30 \mathrm{ml}$

$15-20 \mathrm{gtt}($ drops $)=1 \mathrm{ml}$

House hold system is important for clients rather than using it in the laboratory or in scientific works since it is not accurate [2].

NB: Important relationship for water at STP (standard temperature $\left[23^{\circ} \mathrm{C}\right]$ and pressure $\left.[15 \mathrm{psi}]\right)$

$1 \mathrm{cc}=1 \mathrm{ml}=1 \mathrm{~g}$, one liter of water $=1 \mathrm{~kg}[6]$.

\section{Drug formulations}

Any drug contains one or more active ingredients and other inactive substances such as: excipients, vehicles, flavoring agents, or preservatives. These inactive substances play a role in stability of the drug, ease of administration or they may affect other pharmacological properties of the drug. Pharmaceutical companies manufacture drugs in different forms. Drug formulation can be solid, semisolid, or liquid $[2,15]$.

Drug which are Solid formulations are Powders, Granules, Tablets, Capsules and Bolus.

Powder: contain one or mixture of two or more drugs in a dried or finely pulverized form. It can be prepared for external use or can be mixed with food or water or reconstituted for injection by sterile fluid [15].

Granules: are small aggregate of powder held together by a binding agent. Their use is the same as powders [2].

Bolus: A single, relatively large quantity of a substance intended for therapeutic use [15].

Capsules: a drug formulation in which the drug (solid or semisolid or liquid) is contained in an external shell. The shell which may be made up of gelatine or glycerine will dissolve in the stomach or in the upper part of the intestine. The capsule helps to mask unpleasant (unpalatable) taste of the drug. The disadvantage of capsule is that it cannot be broken, to give a divided or lower dose to an animal [2].

Drugs which are semisolid drug formulations are lotions, ointments, cream, paste or gels which are prepared for local or oral use [19].

Lotions: are solutions or suspensions of soothing substances to be applied to the skin [2]. 
Ointment: is a greasy, semisolid preparation that contains dissolved or dispersed drug. Antibiotics and anti-inflammatory agents can be prepared in the form of ointments. Common examples are eye or ear ointments [6].

Cream: is a semisolid emulsion formulated for application to the skin or mucous membranes. Example: Udder cream [2].

Paste: is a semisolid preparation slightly thicker and less greasy than ointment [15].

Drugs which are liquid formulations are prepared either in the form of solution or suspension. Solution is a homogeneous mixture of two or more substances; prepared as syrups (water and sugar) or injectors. It can be aqueous or alcoholic solution depending on the solvent in it. It doesn't settle or precipitate if it stands still for a long period of time. Solutions may be available in different containers (ampoule, vial or bottle) [1].

Ampoules: are a small glass container intended for single use, the neck is broken to get the drug.

Vials: are glass containers with rubber stopper for single or multiple doses.

Bottles: are glasses or plastic containers with larger volume than vials [2].

Suspension is a fluid containing solid particles that are sufficiently large for sedimentation. It should be shacked before use [6].

\section{Expression of strength of solutions}

Strength shows the concentration of ingredients in a mixture or a solution containing two or more substances. There are two important components in expressing the strength of a solution. Solute is a chemical substance dissolved in solvent that is usually present in small amount. Solvent (diluents) is a liquid used to dissolve other chemicals that is usually present in large amount. The amount of solute and solvent in a mixture indicates its strength. There are different methods used to express the strength of solutions. The most commonly used methods are parts per notation, percentage and ratio [2].

\section{A) Parts-per notation}

The parts-per notation is used as a measure of the concentration of a component substance in a mixture of substances and usually when the concentration is very small. The most commonly used parts-per notations are part per million (ppm), parts per billion (ppb), parts per trillion (ppt) and part per thousand (pps) [6].

Parts per million refers to a number of parts of one substance in one million parts of the solution. For example: $5 \mathrm{ppm}$ chlorine in water is 5 gram of chlorine in one million gram of water $(1,000,000$ milliliters at standard temperature and pressure) [2].

Note: $1 \mathrm{mg} / \mathrm{kg}=1 \mathrm{ppm} ; 1 \mathrm{~mm}^{3} /$ litre $=1 \mathrm{ppm} ; 1 \mathrm{mg} /$ litre $=1$ ppm. [2]

- One part per hundred is generally represented by the percent (\%) symbol and denotes one part per 100 parts, one part in $10^{2}$, and a value of $1 \times 10^{-2}$.

- $\quad$ One part per thousand (pps) denotes one part per 1000 parts, one part in $10^{3}$, and a value of $1 \times 10^{-3}$.

- $\quad$ One part per billion (ppb) denotes one part per 1,000,000,000 parts, one part in $10^{9}, 1 / 1,000,000,000^{*} 100 \%=0.0000001 \%$ (or $1 \%=$ $10,000,000 \mathrm{ppb}$ ) and a value of $1 \times 10^{-9}$. One part per trillion (ppt) denotes one part per $1,000,000,000,000$ parts, one part in $10^{12}$, and a value of $1 \times 10^{-12}$ [6]

\section{B) Percentage $(v / v, w / v, w / w)$}

I. Percent volume in volume $(\mathrm{v} / \mathrm{v})$ : the number of milliliters of a drug in $100 \mathrm{ml}$ of a solution $(1 \% \mathrm{v} / \mathrm{v}=1 \mathrm{ml} / 100 \mathrm{ml})$.

II. Percent weight in weight (w/w): the weight in gm of a drug in $100 \mathrm{gm}$ of the mixture $(60 \% \mathrm{w} / \mathrm{w}=60 \mathrm{gm} / 100 \mathrm{gm})$.

III. Percent weight in volume $(\mathrm{w} / \mathrm{v})$ : the weight in grams per $100 \mathrm{ml}$ of a solution (dextrose $5 \% \mathrm{w} / \mathrm{v}=5 \mathrm{~g} / 100 \mathrm{ml}$ ) [19].

\section{C) Ratio}

Ratio is expressed as 1:1000 which means 1 unit of a drug in 1000 unit of a solution. [2]

Changing the strength of solutions: The strength of a solution can be changed either by dilution or concentration. Dilution is making a solution less concentrated for application as a drug or laboratory reagent. This is done by adding a solvent (diluents), or a mixture with solutions or mixtures of lower strength. Concentration is increasing the strength of a solution by addition of the active ingredient (solute), evaporation of the diluents or a mixture with solutions or mixtures of higher strength. If the amount of active ingredient remains constant, any change in the quantity of solution or mixture of solids is inversely proportional to the percentage or ratio strength that is the percentage or ratio strength decreases as the quantity increases [2].

As Problems in dilution or concentration are generally solved by the following equation:

$(\text { Quantity })_{1} \times(\text { Concentration })_{1}=(\text { Quantity })_{2} \times($ Concentration $)$ ; $\mathrm{Q}_{1} \times \mathrm{C}_{1}=\mathrm{Q}_{2} \times \mathrm{C}_{2}$

For calculating other quantity, determining the quantity of active constituent (solute) is needed and then calculating the quantity of the available solution (usually concentrated or stock solution) that will provide the needed amount of the constituent [19].

\section{Dose calculation}

Dose calculation is crucial for any veterinary clinical practices. Over dose is dangerous for the patient and encore extra-cost. Under dose is ineffective and promote the development of drug resistance. Factors that affect dosage are related with the patient or the drug. The patient factors include body weight, species of animal, sex, age, physiological status and pathology. Some of the factors related with drug are type of the drug and concentration of the active ingredient [1]. To calculate the dose, you should know the standard dose (mg/ $\mathrm{kg}, \mathrm{ml} / \mathrm{kg}$, unit $/ \mathrm{kg}$ or dilution rate for a solution), the concentration of the active ingredient ( $\mathrm{mg}$ in $\mathrm{ml}$ or $\mathrm{g}$ ) and the body weight of the animal [6] (Figure 6).

Beef cattle: Heart girth and body length measurement are then used to calculate the animal's weight. The weight estimation formulas described below are almost always more accurate than visual observation in determining an animal's weight [6] (Figure 7). 


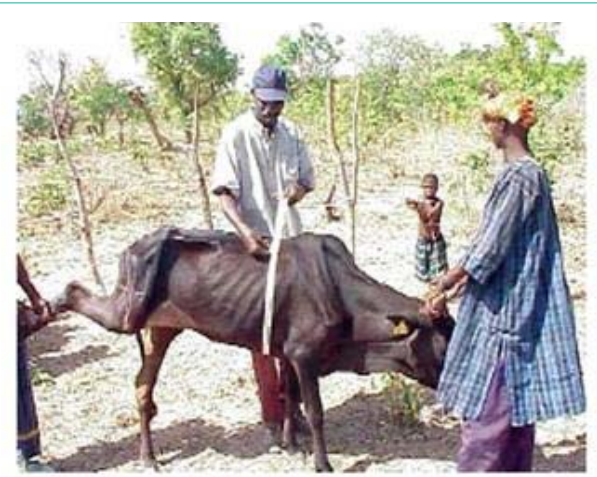

Picture 12. barymetry for weight estimation.

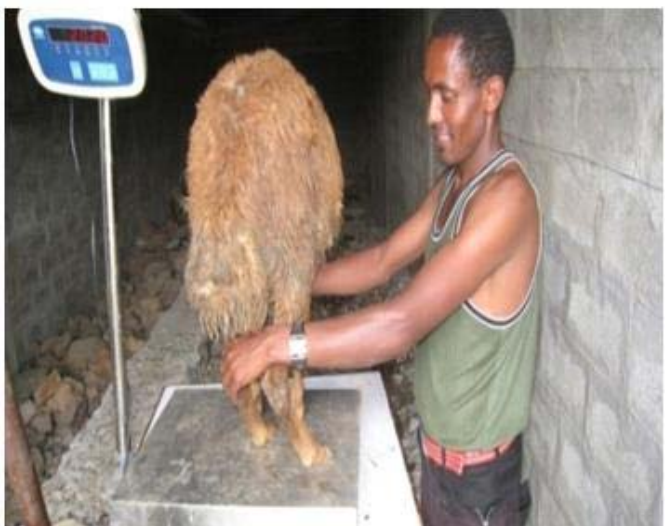

Figure 6: Weighing the animal by heart girth and sensitive digital balance.

Measure the length of body, from the point-of-shoulder (A) to the point-of-rump or pin bone (B). Then Measure the circumference or heart girth $(\mathrm{C})$, measure from a point slightly behind the shoulder blade down the fore-ribs and under the body behind the elbow all the way around. After these measurements are made in inches, use the following formula, (Heart girth X heart girth X body length) $\div 300=$ weight in pounds [19].

For sheep and goats, use the same method described for beef cattle. When working with unshorn sheep, be sure to part or compress the wool to insure an accurate heart girth measurement [2].

Horses: Measure the length of body from, from the pointof-shoulder (A) to the point-of-rump (B). Then Measure the circumference (heart girth) of body (C). Measure from the base of the withers, down under the belly, just behind the elbow and foreleg, and all the way back around. After these measurements are made in inches use the following formula, (Heart girth $\mathrm{X}$ heart girth $\mathrm{X}$ body length) $\div 330=$ weight in pounds [19] (Figure 8 )

Tips for increasing Accuracy and Safety during weight measurement: Make certain the animal is standing squarely on level ground, Have someone stand on the opposite side to help with the girth measurement, Make sure the tape lays flat and is not twisted, Pull the tape snug, When using a weigh tape, position the tape according to the manufacturer's directions, A cloth measuring tape is preferred, You may need to restrain the pig or some feed may help you get the needed measurements, Be calm, don't rush in. Make sure the animal is comfortable with the measuring tape, When monitoring

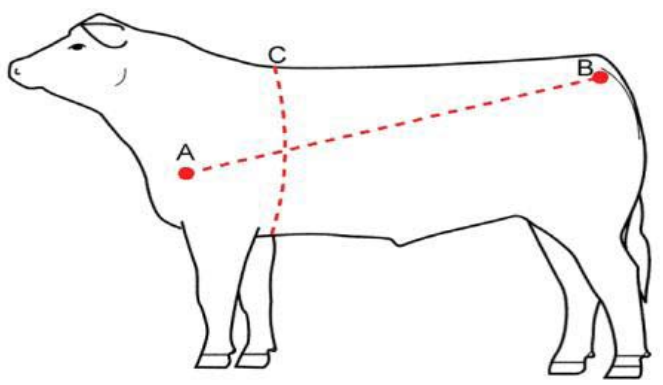

Figure 7: Beef Cattle.

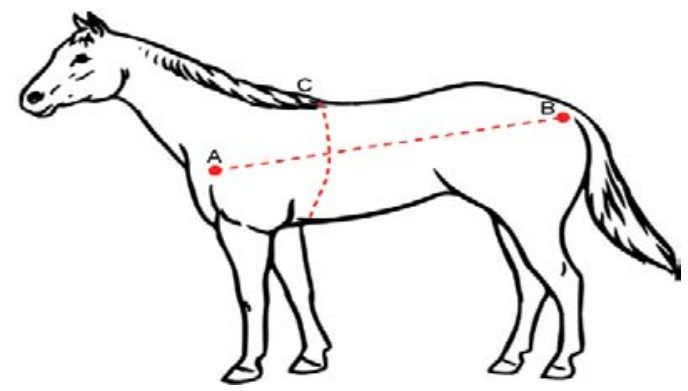

Figure 8: Horses.

an animal's weight over time, it is best to have the same person using the same method, By following a set procedure you will be able to monitor change that can be used as an indicator of health, The weight estimation formulas and weigh tapes may be used effectively for many animals, but are not highly accurate for pregnant animals or those with extreme conformational irregularities and Keep a record that you can refer back to over time $[1,2,6]$.

Formula to calculate dose: Unit (amount) needed = body weight $\mathrm{X}$ dose rate. You should always notice the unit of measurement. Example: How many mg of Amoxicillin are needed for a $10 \mathrm{~kg}$ dog if the dose is $20 \mathrm{mg} / \mathrm{kg}$ ? mg needed $=10 \mathrm{~kg}$ x $20 \mathrm{mg} / \mathrm{kg}=200 \mathrm{mg}$ (kilograms cancel out).

Liquid dosage in $\mathrm{ml}=$ Standard dose in $\mathrm{mg} / \mathrm{kg} \mathrm{X}$ body weight in $\mathrm{kg} /$ Concentration of the drug in $\mathrm{mg} / \mathrm{ml}$ [19].

\section{Withdrawal period and veterinary drug residue}

It is the interval necessary between the last administration to the animals of the drug under normal condition of use and the time when treated animal can be slaughtered or the production of safe foodstuffs. Drug withdrawal time is the time required for drug residues to reach a safe concentration for human or animal consumption, and defined as maximum residual limit. Depending on the drug product, dosage form, and route of administration, the withdrawal time may vary from a few hours to several days or weeks. To ensure that drug residues have declined to a safe concentration following the use of drugs in animals, a specified period of drug withdrawal must be observed prior to providing any products for human consumption. Failure to follow recommended withdrawal time is often implicated in residual problems. It is advisable to follow recommended withdrawal time to avoid residual effects of drugs in the food of animal origin; that is, we have to check and observe the withdrawal period laid down 
for the particular medicine and food animals should not be sold for slaughter, or slaughtered before the end of withdrawal period [11].

In general, slaughter and feeder animals should not be treated with a veterinary drug if the withholding period exceeds the expected date of arrival overseas. However, there are two exceptions: where treatment is specified in the importing country's protocol; or where an animal has already been loaded for export, treatment is necessary for animal welfare reasons, and there are no drugs available with comparable efficacy and a shorter withholding period [23].

Whenever antibiotics or other drugs are administered to food producing animals either by the veterinarian or by the owner, the veterinarian must inform the owner about the withdrawal periods for the drugs used in order to avoid residues in animals and their products (meat, milk, eggs and honey), such information must be given verbally and in writing. if animals are delivered for emergency slaughter within the withdrawal period, information regarding the withdrawal period, as described above, must accompany the animal to the slaughterhouse [2]. Withdrawal period may be affected by different factors.

Route stated on the label is followed or not: withdrawal times are only applicable if the route stated on the label is followed. for example, liquamycin lp given intramuscular has a withdrawal time of 60 hours following the last treatment. If given in the route other than indicated on the label, the withdrawal time may be other than indicated $[16,17]$.

Amount administered: volume administered per injection site is important. For example, the liquamycin label states "do not administer more than 10 milliliters per site". If you administer more than $10 \mathrm{cc}$ the withdrawal time may be other than indicated [6].

Method of treatment: Intramuscular injections require a 1.5 inch needle to insure that the product is injected into the muscle. If the needle is not into the muscle and the product goes into the fat or under the skin the adsorption is affected and the withdrawal time is not known. Repeated injections in the same area interfere with adsorption of the product. Choose a new site for each treatment $[16,17]$.

\section{Veterinary pharmacovigilance}

Pharmacovigilance is the science and set of activities relating to the detection, evaluation, understanding and prevention of adverse effects or any other possible drug-related problems. The scope of veterinary pharmacovigilance is mainly the safety and efficacy in animals and safety in people. Pharmacovigilance is important to continuously monitor the safety and efficacy of a drug after it is granted market authorization [24]. The information collected allows the on-going assessment of the benefit-risk of the veterinary drug in relation to its target population and throughout its life-cycle. The existence of a reliable pharmacovigilance system supports the benefitrisk assessment approach to licensing, and avoids the drawbacks of a zero risk approach. Pharmacovigilance has aims for early detection of unknown safety problems, identification of risk factors, quantifying risks, preventing patients from being affected unnecessarily and detection of unexpected therapeutic benefits [2].

\section{Terminologies on Veterinary pharmacovigilance}

An adverse event: It is any observation in animals, whether or not considered to be product-related, that is unfavorable and unintended and that occurs after any use of veterinary drugs (off-label and onlabel uses). Included are events related to a suspected lack of expected efficacy according to approved labeling or noxious reactions in humans after being exposed to veterinary drug(s) [2].

Adverse reaction: It is defined as a response to a veterinary drug which is noxious and unintended, and which occurs at doses normally used in animals for prophylaxis, diagnosis, or therapy of disease or for the modification of physiologic function [24].

Serious adverse event: It is any adverse event which results in: death, life-threatening, results in persistent or significant disability/ incapacity, congenital anomaly or birth defect [2].

Unexpected adverse event: it is an adverse event of which the nature, severity or outcome is not consistent with approved labeling or approved documents describing expected adverse events for veterinary drugs [2].

To monitor adverse drug effects $\mathrm{s}$ there are two basic methods:

- Passive surveillance: Spontaneous (voluntary reporting system);

- Active surveillance: Post-Marketing Surveillance, prescription event monitoring, cohort studies which could be intensive /targeted hospital monitoring, case - control studies and record linkage [2].

Report the adverse event immediately after it occurs, if possible, take the decision to report whilst the patient animal is still with you, which gives a chance to reporter to clear any ambiguity by requestioning owner or examining the patient animal. Think about any other factors which may contribute in causing the event such as: other prescribed drugs, self-medication, herbal products, feed, and chemicals [2]. All reports must have the following four data elements (components of an adverse report): animal information, adverse event description, suspected $\operatorname{drug}(\mathrm{s})$ and information about the reporter. Always write legibly. One animal or one human being, or a medically appropriate group exhibiting similar clinical signs should be included in a single report. Adverse drug event should be reported by all animal health professionals, animal health institutions using veterinary drugs (government and private veterinary clinics, veterinary pharmacies, and research and education institutions), marketing authorization holders (manufacturers and/or local agents) and animal owners [2].

Product quality defect: It is quality problem of products with suspected contamination, questionable stability, defective components, poor packaging and labeling and therapeutic failure [25].

Market authorization holder: The commercial party who are working according to the authority that responsible for the pharmacovigilance of the veterinary medicinal product [25].

\section{Veterinary drug resistance}

Drug resistance is reduction in effectiveness of a drug in curing a disease or condition. It occurs when the drug is unable to inhibit or kill the disease causing organism due to the development of a mechanism to cope the effect of the drug. Antimicrobial resistance 
is the resistance of a microorganism to an antimicrobial drug to which it was previously sensitive. Resistant organisms (they include bacteria, viruses, and some parasites) are able to withstand attack by antimicrobial medicines such as antibiotics, antiviral, and antmalarial [25].

Historically Antimicrobial Resistance (AMR) was first described in 1940 in Bacillus coli (now known as Escherichia coli) by Abraham and Chain (1940), shortly before the start of the use of penicillin to treat infectious diseases in humans in the same and not long after its discovery by Fleming (1929). Since most antimicrobials in clinical use are naturally produced by soil microorganisms, such microorganisms are the source of many resistance genes now found in clinically relevant bacteria, as was demonstrated more than 40 years ago [21].

There is growing evidence that AMR is in fact an ancient and natural part of the genome of environmental bacteria. However, it is important to realize that AMR was very rare in clinical isolates predating the introduction of antibiotics, as demonstrated in a retrospective analysis by Hughes and Datta (1983), which provides strong evidence for the central role in the emergence and spread of AMR as a public health threat [26]. In a 2015 Washington State survey, $91 \%$ of veterinary prescribers agreed that antibiotic resistance is an important public health issue. In veterinary medicine, we are faced with resistant infections for which there are few effective antibiotics [21].

\section{Causes of veterinary drug resistance}

Unnecessary use of veterinary drugs (inappropriate duration), refugia, inappropriate dose (under dose, over dose), use of irrational antimicrobial fixed dose drug combinations could be some of the possible Causes of veterinary drug resistance [27]. Although the pace of resistance development is influenced by operational, genetic and biological factors, the most important elements accelerating the rate at which drug resistance develops are the operational factors. Farmers play an important role in the management of drug resistance through the selection of different drugs and administration protocols implemented [27].

Factors contributing to the development of drug resistance:

- Knowledge gaps about drugs

- Expensiveness and time-consuming of new drug development.

- Decreases interest of pharmaceutical industries in antimicrobial research and development.

- $\quad$ Expectation and interaction of prescribers and owners; many owners believe (expect) that new and expensive drugs are more efficacious than older agents.

- Economic incentive problems.

- Regulatory condition.

- $\quad$ Self medication, may brings inadequately dosed.

- Owners compliance with the recommended treatment; May forget to give medication, Interrupt the treatment when he/she feels his/her animal gets better, Unable to complete the full course of the treatment.
- Frequent employment of the same chemical group in the therapy of infections and using of drugs in a lower dose than is required therapeutically $[14,28]$.

In the past, strategic or prophylactic mass treatments of livestock have been the rule. This practice is certainly responsible for many of the drug resistance problems, an example of which is the drench and move system, whereby all animals in a flock are treated before they are moved to clean pastures containing few or no worms in refugia. Mathematical modeling has shown that it is possible to delay the development of drug resistance by not treating part (e.g. 20\%) of the herd or flock [14]. The phenomenon of refugia, i.e. the proportion of the parasite population that is not exposed to drugs and thus escapes selection for resistance, is a very important factor, whose impact on the development of Ant-helmintic resistance is too often overlooked [28].

The size of refugia will be mainly determined by the fraction of the population treated (i.e. mass treatments versus selective or targeted selective treatments) and the proportion of the worm population present in the environment where it is not subject to drug action (e.g. in the soil). This is in turn influenced by a range of factors including e.g. climate and longevity of the infective stage [14].

There are different factors directly related to the administration of an antimicrobial that affect the occurrence of AMR. These include: the type and formulation of the antimicrobial agent; the dose; the total animal biomass exposed to the antimicrobial (i.e. individual treatment versus mass medication); the treatment interval and the treatment duration. The formulation determines the route of administration but relatively little attention has been given to the association between the antimicrobial formulation and the rise of Multidrug-Resistant (MDR) organisms [26].

\section{Mechanism of antimicrobial resistance}

Mechanism of Antimicrobial Resistance Occur in two ways:

A) Intrinsic or inherent or natural resistance

Intrinsic resistance is inherent to all specimens of the species. In such cases, in general, the gene that encodes the intrinsic resistance is chromosomal. For example, all Gram-negative bacteria are naturally resistant to vancomycin due to their cell wall structure, which differs from Gram positive cell walls [29]. Resistance to penicillin G expressed by most Gram-negative bacteria is a common example; this is due to the complexity of its cell wall with the presence of an outer membrane absent in Gram-positive bacteria [26].

\section{B) Acquired resistance (adaptive)}

Acquired resistance involves a change in the organism's genetic composition via either mutation in the chromosomal DNA or the acquisition of exogenous DNA. Mutations occur randomly at a low frequency, and the mutations can sometimes result in advantageous characteristics that can be selected. For example, mutation accumulation in quinolone targets in DNA gyrase is the main mechanism against quinolone binding [30]. Further phylo-genetic analysis has shed some light on the evolutionary origins of resistance, indicating that bacteria evolved AMR genes long before the antibiotic era and even developed defenses against synthetic compounds. Though bacteria can acquire external DNA by bacteriophage 


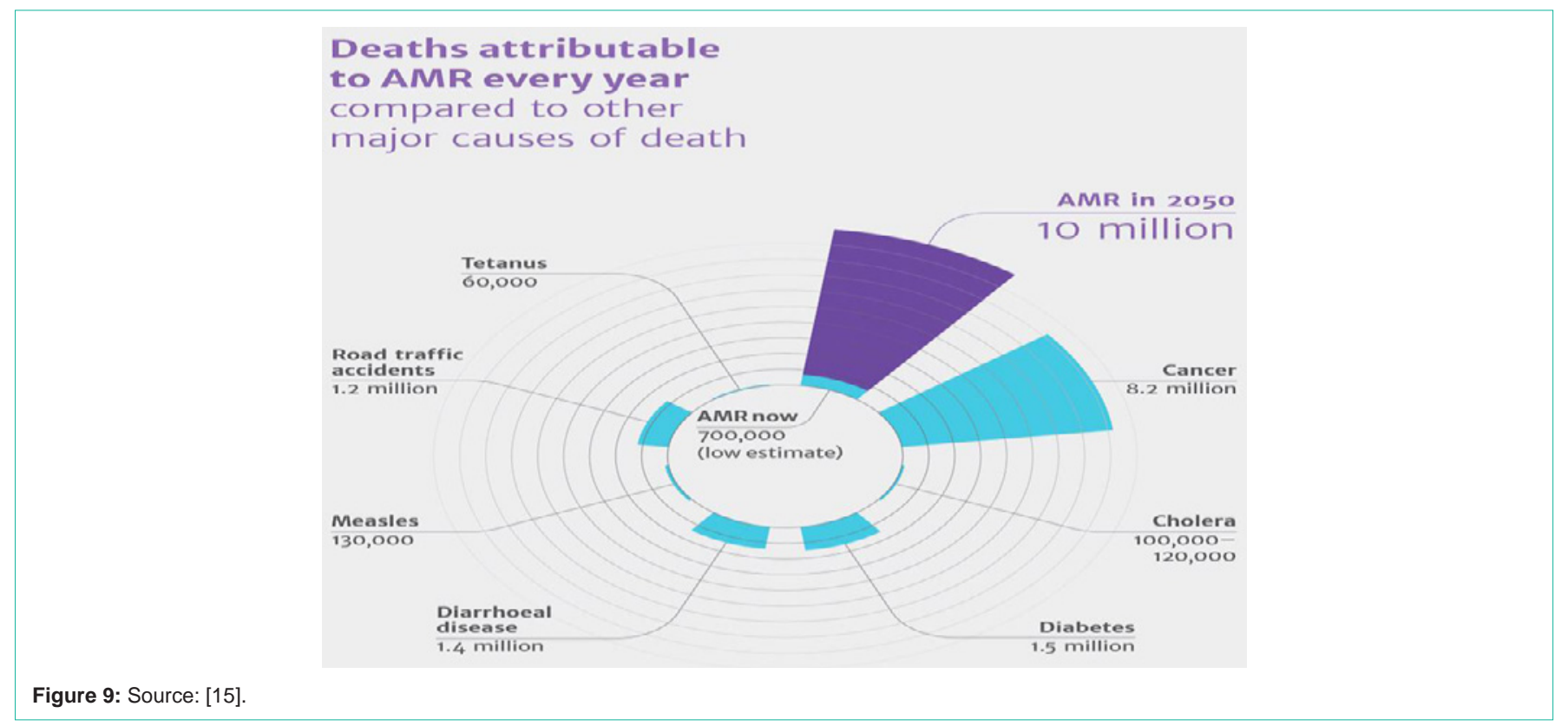

infection and transformation, plasmid mobilization by direct cell-tocell contact, also termed conjugation, is the most common transfer mechanism of antimicrobial resistance-encoding genes [30].

Acquired resistance to antimicrobial drugs can develop in bacteria in two ways: Preexisting genes can mutate, or/and Genes from other bacteria can be horizontally transferred to them [30] (Figure 7,8 and 9).

\section{Impacts of veterinary drug resistance:}

- Increased the costs of treatment,

- Increased morbidity and mortality from infectious diseases and reduced productivity,

- Increased emergence and spread of resistant zoonotic bacterial diseases,

- Many food and animal industries will be affected due to lack of raw materials,

- $\quad$ Reduced socioeconomic status of many individuals globally e.g. Export/import,

- Interfere the control and eradication processes of diseases $[17,31]$.

Prevention of veterinary drug resistance: Fight against AMR requires a coordinated approach between health and livestock sectors on the effective use of antibiotics in humans and animals, Appropriate actions should be taken by all authorization, regulation, distribution, and use of antimicrobials in animal and human health, Avoid inadequate or unduly prolonged use of drugs, Promote use of appropriate dosage regimen, Use as much as possible rapidly acting and selective (narrow-spectrum) antimicrobial agents, use combination of AMAs whenever prolonged therapy is undertaken, example Tuberculosis, Use individual full doses in combination therapy, Know the sensitivity pattern and infectious epidemiology and Enhancing infection prevention and control [17,31].
Across the EU as a whole, approximately $90 \%$ of all antimicrobials prescribed to livestock are given via the oral route. Administration of antimicrobial agents through either bulk animal feed or the drinking water supply, rather than by injection, has major economic and ergonomic advantages. In addition, potential unwanted effects of injection such as carcass damage or residues at an injection site are avoided. In some situations (e.g. commercial chicken production, aquaculture) oral administration to the whole group of animals is almost always the only feasible option [32].

The World Health Organization (WHO), developed the WHO Global Strategy for Containment of Antimicrobial Resistance Key recommendations to address the need for mitigating AMR were listed as follows: Key recommendations emanating from the 25 expert reports: Increase awareness of the antibiotic resistance problem, Improve surveillance of antibiotic resistance, Improve antibiotic use in people, Regulate antibiotic use in animals, Encourage new product development, Increase resources to curb antibiotic resistance in the developing world, Increase funding for surveillance, research and education [32].

Particular interest for veterinarians is the recommendation to regulate antibiotic use in animals. The experts further identified key stakeholders and each of their respective potential contributions to support this particular recommendation: Recently since 2006, the European Union project is established which is known as PARASOL. The PARASOL Project aims to reduce the need for drugs by developing Target Selective Treatment only for animals showing clinical evidence of parasitic disease or reduced productivity. Animals with low worm burdens do not show symptoms and therefore do not require treatment. In addition, these strategies will reduce the risks of residues in food and in the environment and provide a parasite population in refugia to limit the development of anti-helmintic resistance [14].

\section{Relation between veterinary drugs and public health}

By eating animals and animal products (meat, milk, eggs, etc.), 
humans are liable to consume whatever chemicals the animal has consumed or been exposed to veterinary drugs, but also insecticides used on the animal, herbicides and fertilizers used on pastures and chemical additives used in its feed. Some of these substances are toxic (in particular, pesticides and herbicides), and some are undesirable in other ways for use on animals whose products are consumed by humans [11].

The human health consequences of chemical residues in animals is a subject which is hotly debated, between farmers, chains of food suppliers, pharmaceutical companies, drug regulators, public health administrators and consumer groups. Not only is there disagreement among interest-groups within countries, but between countries the impact of a drug ban on trade in animal products ensures that a country's motives for banning certain drugs will be questioned. The European Union, for example, in 1999 banned all antibiotics used on humans from being used on Animals as Growth Promoters (AGPs), and similarly the EU has banned the use of Hormonal Growth Promoters (HGPs) on cattle [11].

Under the normal physiological conditions, following administration of a drug to an animal, most drugs are metabolized in order to facilitate elimination, and to a large extent detoxification as well. In general, most of the parent product and its metabolites are excreted in urine and a lesser extent via faeces. However, these substances may also be found in milk and eggs, and in the meat $[17,31]$.

There are many factors influencing the occurrence of residues in animal products such as drug's properties and their pharmacokinetic characteristics, physicochemical or biological processes of animals and their products. The most likely reason for drug residues might be due to improper drug usage and failure to keep the withdrawal period. The major public health significances of drug residue are development of antimicrobial drug resistance, hypersensitivity reaction, carcinogenicity, mutagenicity, teratogenicity, and disruption of intestinal normal flora [17,31].

It has been noted that different residue levels can be found in different tissue positions based on site and route of administration. The most likely reason for drug residues may result from human management, such as improper usage, including extra-label or illegal drug applications. However, the most obvious reason for unacceptable residues might be due to failure to keep to the withdrawal period including overdose and long acting drugs. Inadequate good sanitary care during animal or product transportation, including the cross contamination of animal feeding stuffs with inadvertently applied drugs, environmental and animal to animal transfer of drugs may also cause residues $[17,31]$.

Drugs mixed into drinking water or food is a common method of administration used in pig and poultry farms, often to reduce the stress of handling individuals. The addition of antibiotics into animal feed is a controversial matter, particularly if they are used as a growth promoter or for the prevention of disease. However, an antibiotic used in feed for therapy to treat a large group of sick animals, provided they still have an appetite, is considered a good way to treat thousands of individuals. Tons of food can be so medicated, having the antibiotic inside it. Drugs for external treatment can be poured, shampooed, sponged or rubbed on and in some cases the whole animal can be placed in a bath dip of drug in solution. This dipping is a common method used for treating sheep and cattle for parasites [33].

A caveat is a warning or proviso of specific stipulations, conditions, or limitations about the use of the drug; one reason being that many drugs is poisonous if used incorrectly. Drugs wrongly used can, in some circumstances, be lethal. Examples of the caveats about drugs are as follows: the drug should have little or no side effects or deleterious effects on the animal being treated, no deleterious effects on the person managing the animal, none on the person who may consume the animal if the animal is one designed to be eaten and little or no deleterious effects on the environment as whole [33].

Inspection procedures nowadays include laboratory checks to look for substances such as growth promoters, hormones, antibiotics or chemicals used in the production of the meat, milk, eggs and other foodstuffs of animal origin with the aim of significantly reducing the risk of the public consuming harmful chemicals [33].

The challenges of the nutritional transition to animal proteinbased diets and the rise of antimicrobial resistance are thus closely linked: The use of antimicrobials as growth promoters and therapeutics to support the growing demand for meat is placing ever greater selection pressure for resistant strains of bacteria to evolve. Whereas trends in antibiotic consumption in humans are now being tracked in most high-income and some middle-income countries through databases on antibiotic sales, antimicrobial consumption in livestock has received comparatively little attention. Expert opinion suggests that global consumption of antimicrobials in animals is twice that of humans $[17,31]$.

Another important Challenges faced by developing countries including Ethiopia regarding surveillance systems in the usage of antimicrobials. A satisfactory and comprehensive survey is needed to understand the epidemiology of antimicrobial usage in both animals and humans $[17,31]$.

Drug-resistant bacteria in animals may harm human health via three main routes of transmission. First, humans may consume or otherwise come in contact with food that is contaminated with drug-resistant bacteria, which may occur at many processing points, including sale, storage, and preparation. Second, humans may come in contact with resistant bacteria via live farm animals, manure, or shed material such as feathers. Drug-resistant bacteria may infect producers, processing facility workers, or others who live or work on farms. Third, infected people can then transmit illness to others [34].

Tracking the actual transmission of antimicrobial-resistant diseases due to production-purpose antibiotics between animals and humans is difficult, involving several steps.

- First, researchers must find an association between the proliferation and persistence of resistant bacteria in animals from production-purpose doses of antimicrobial drugs.

- $\quad$ Second, researchers must show the presence of resistant pathogens in animals or animal products exposed to productionpurpose levels of antibiotics.

- Third, studies must link the transmission of these pathogens 


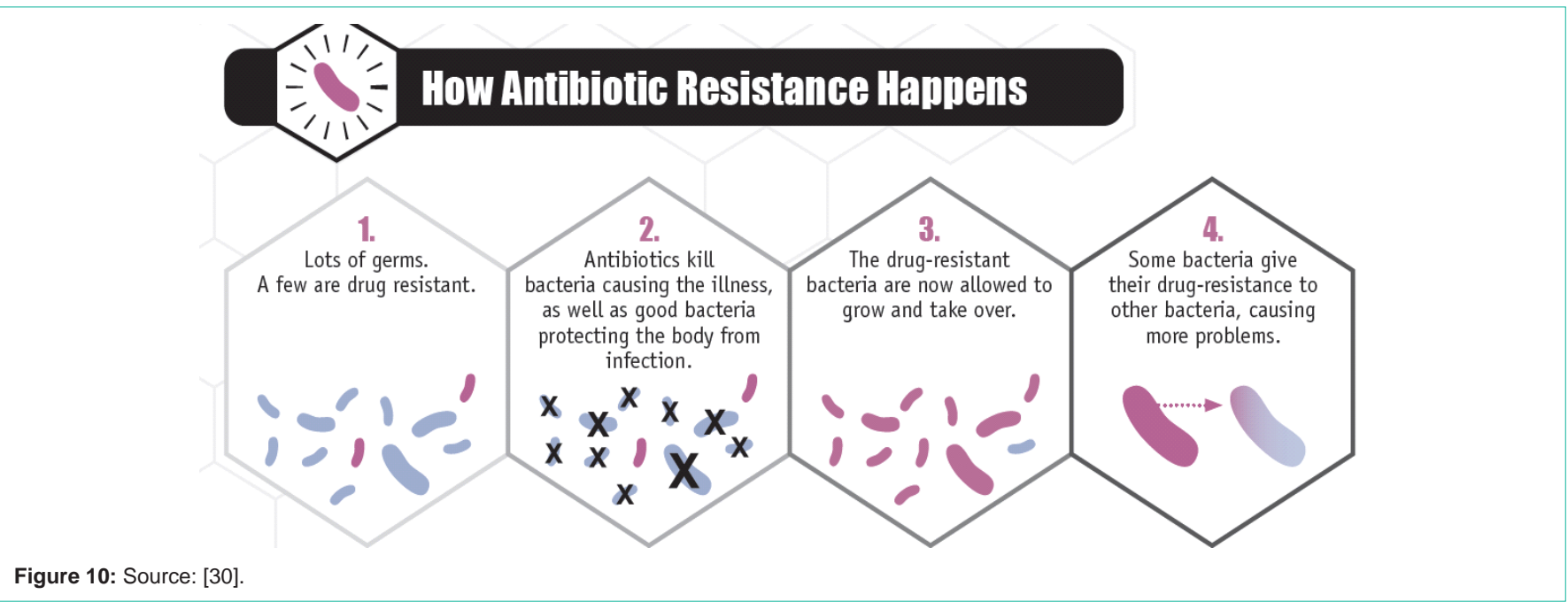

Figure 10: Source: [30]

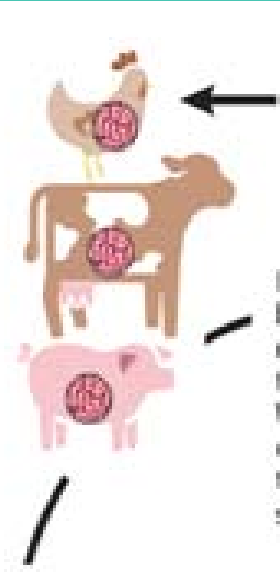

Fertilizer or water. coetaining animal feces and drug-resistant bacteria is used on food crops.

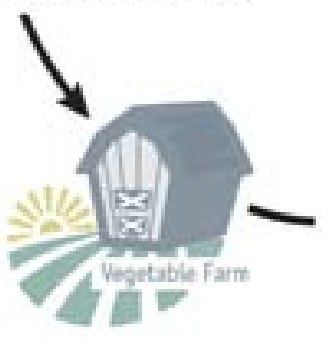

Animals get. antiblotics and develop resistant. bacteria in theif guts.

Drug-resistant bacteria can remain on meat from animals. When not handled or cooked properly. the bacteria can spread to humans.
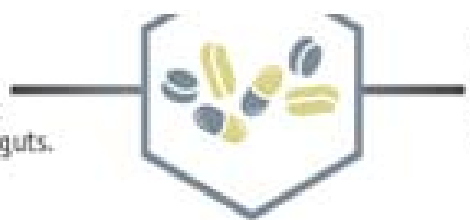

George get: antibiotics and develops resistant bacteria in his gut.

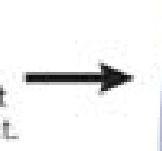

(v)
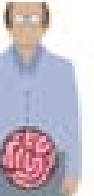

George stays at home and in the general community. Spreads resistant bacteria.

consons

hospital, nursing home of other inpatient care facility.

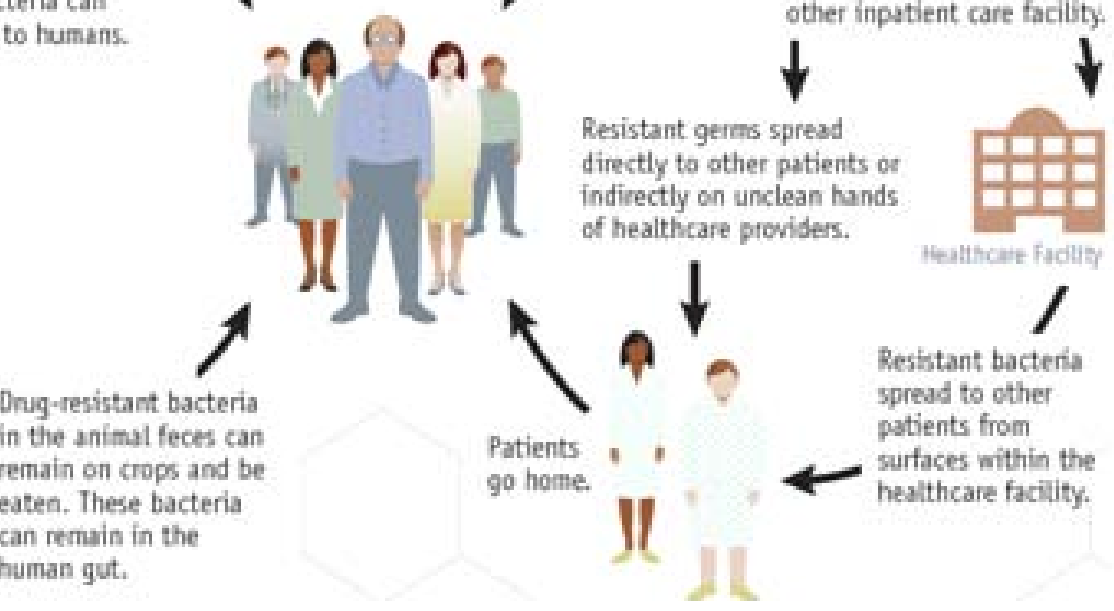

Figure 11: Source: [19].

to humans. Finally, researchers must diagnose human diseases caused by these pathogens. Despite the difficulty in making all of these linkages, studies that trace human infections by drug-resistant pathogens to animal sources do exist [35].

Antibiotic usage in animal results in the developments of human MARSA which results in amplified human illness, death, reduced effectiveness of associated antibiotics used for human, increased healthcare costs, increased potential for carriage and dissemination of pathogens within human populations and facilitated emergence of resistant human pathogens [36]. The research estimated that, under the circumstances enumerated below, 300 million people are expected to die prematurely because of drug resistance over the next 35 years and the world's GDP will be 2 to $3.5 \%$ lower than it otherwise would be in 2050. This means that between now and 2050 the world can expect to lose between 60 and 100 trillion USD worth of economic output if antimicrobial drug resistance is not tackled. This is equivalent to the loss of around one year's total global output over the period and will create significant and widespread human suffering. Furthermore, in the nearer term we expect the world's GDP to be $0.5 \%$ smaller by 


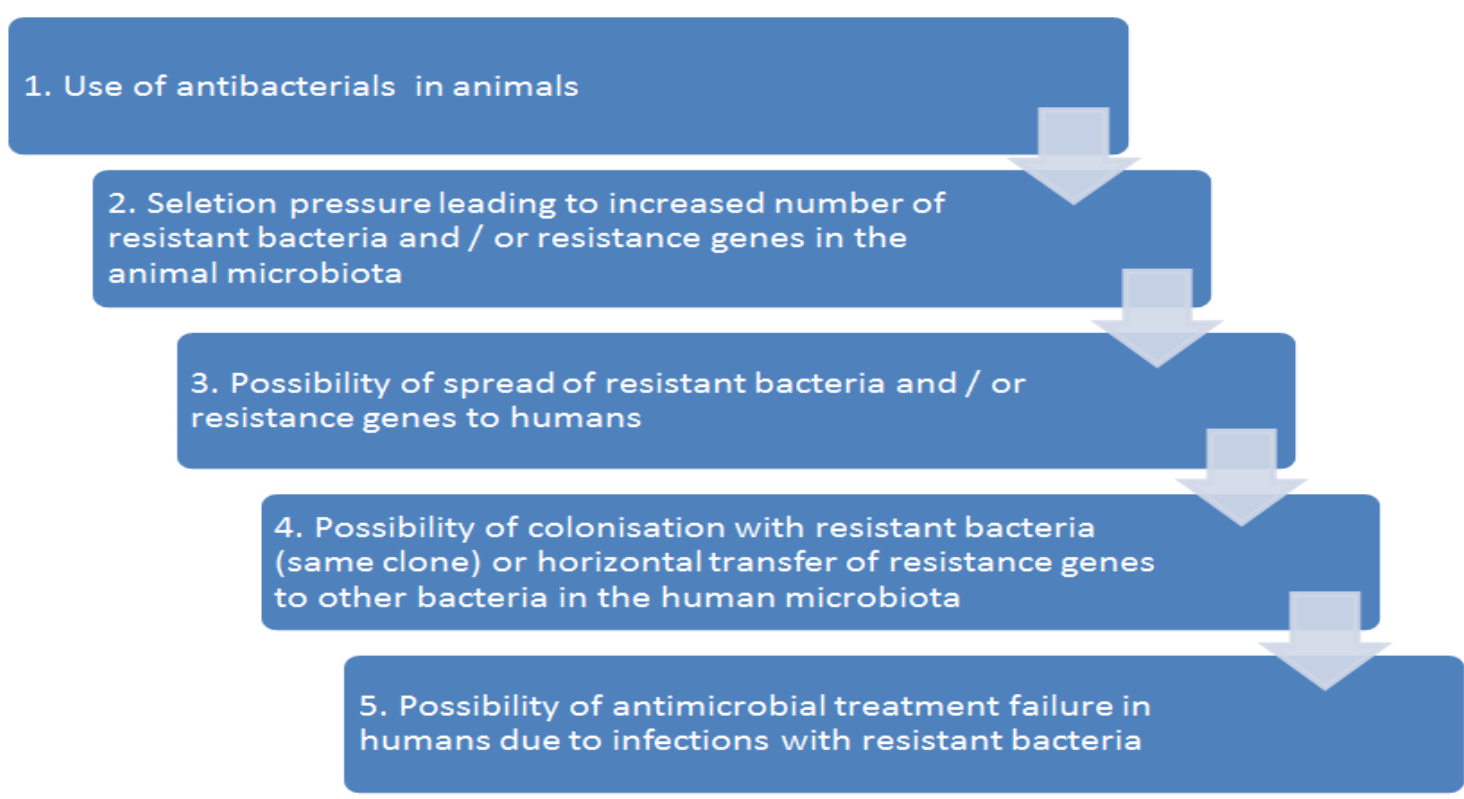

Figure 12: The chain of events that may follow from use of antimicrobials in animals resulting in compromised antimicrobial treatment in humans.

2020 and $1.4 \%$ smaller by 2030 with more than 100 million people having died prematurely. Acquirement of resistance bacterial species for human being can be from food of animal origin and infected animal. Methicillin-resistant Staphylococcus Aureus (MRSA) is resistant bacteria which are not affected by enzyme penicillinase. Currently animals are a source of human MRSA which is responsible for zoonotic implication [36].

There are two main areas of concern about the human health effects of antibiotic use in livestock production: Antibiotic residues in food products, which may cause allergic reactions and digestive problems in humans, were the focus of early regulation of antibiotics in food animals. The FDA therefore established minimum intervals between the last dose of antimicrobials and the time of slaughter to prevent such residues in meat [32]. The threat of drug-resistant bacteria, Studies have reported the appearance of drug-resistant bacteria in food animals shortly after antibiotic use in production began, though recent studies have shown antibiotic resistance in the natural environment predates production uses [34].

Public health risk from vet drug residues are Anaphylaxis/ food allergies, Reproductive disorders e.g. birth malformation, genotoxicity, Development of Antimicrobial Resistance (AMR) through food chain and Long term effects e.g. carcinogenesis [37].

Risk factors responsible for the development of residue are the following.

- $\quad$ Age of animal: Weaning status and, to a lesser extent, the age of the animal affect drug disposition.

- $\quad$ Feeding: Diet can affect the bioavailability of drugs.

- $\quad$ Diseases status

- Pharmacodynamic and pharmakokinetices nature of the drugs $[17,31]$.

\section{Economic impact of antibiotic drug resistance}

Because of their increased survivability in the existence of antibiotic meditations, infectious agents keeping AMR received an enhanced possibility for spread, occurrence. Which cause in their supremacy over the predominant microorganism within animal host populations, resulting in advanced rates of spread as related to the vulnerable bacterial species. Initial research, looking only at part of the impact of AMR, shows that a continued rise in resistance by 2050 would lead to 10 million people dying every year and a reduction of $2 \%$ to $3.5 \%$ in Gross Domestic Product (GDP). It would cost the world up to 100 trillion USD. An increased medical charge is extra vital result of antibiotic resistance. Increased prices may be owing to the prerequisite for supplementary antibiotic treatments, longer hospitalization, more diagnostic tests, higher professional costs and more pain management or Antibiotic resistance due to an antibiotic used in animals may result in reduced efficacy of most or all members of that same antibiotic class [36] (Figure 10).

Recent study from seven European countries (Norway, Sweden, Denmark, Austria, Switzerland, The Netherlands, and Belgium) showed a strong correlation between consumption levels for eight classes of antimicrobials and the prevalence of antimicrobialresistant commensally Escherichia coli in pigs, poultry, and cattle. Several works additionally suggested that repeated exposure to low doses of antimicrobial agents the context in which growth-promoting antimicrobials and prophylactic are administered creates ideal conditions for the emergence and spread of ARBs in animals [17,31].

\section{Conclusion and Recommendation}

Although veterinary drugs have played a great role in therapeutic, prophylactic, control and prevention of disease in animals, and promote the growth of food animals, its use is associated with problems such as development of resistance and residual effects in food animals. These adverse effects are generally due to irrational 
use of drugs such as misuse, extensive use, failure to keep strict adherence of withdrawal and withholding time of drugs. Rational use of drugs in veterinary medicine has numerous benefits, such as increasing efficacy, decreasing the potential adverse effects, reducing risk of drug residue and combating development of microorganism's drug resistance. According to the review, things which aggravates irrational veterinary drug use are: incorrect diagnosis and drug administration of diseases, lack of laboratory tests, low prescribers, educational status, lack of standard veterinary treatment guide lines, presence of few essential drugs and absence of standard case paper which has to contain all necessary information of routine clinical examination and treatments. The development of resistant microorganisms in animal and the presence of drug residue in food of animal origin have significant effect on public health. Antimicrobial usage in food-producing animals is one of the factors that causes the emergence of drug resistance and should be prioritized when tackling the drug resistance issue.

Based on the above conclusion the following recommendations are forwarded:

- Veterinary practice has to be standardized and professionally lead according to the OIE standard guide lines and professional discipline (ethics) through professional development, awareness creation to animal owners and public and regulating the veterinary intervention up to standard. Sustainable training or improving public awareness, regarding with rational vet drug use should be given to the community/live stock owners and vet professional.

- Newly up dated or scientific finding should be informed to the concerned bodies of veterinary. Therefore, veterinary drugs, specially, antimicrobial agents should be judiciously used; and a wide scale study to safeguard the public from drug residual effects and antimicrobial resistance development is recommended.

- To protect the occurrence of drug resistance in addition to proper drug use it is better to try new drug development.

- $\quad$ Strengthening knowledge on AMR through surveillance.

- Reducing incidence of AMR infection.

- Optimizing antimicrobial usage and developing sustainable investment for new AMR interventions.

\section{References}

1. Tony B, Colin C, Phil R. Livestock exports Best practice use of veterinary drugs. 2004; 4

2. Beyene MA, Kebede S, Zeru $\mathrm{H}$. Rational use of veterinary drugs and vaccines first edition prepared by: - veterinary drug and animal feed administration and control authority (vdfaca), under ministry of livestock and fisheries, in collaboration with university of gondar, prepared by vdfaca in collaboration with university of gondar, ethiopia faculty of veterinary medicine contributors. 2016.

3. Beyene T, Endalamaw D, Feyisa A. Evaluation of rational use of veterinary drugs especially antimicrobials and anthelmintics in Bishoftu. Central Ethiopia. 2018; 8.

4. Megerrsa SA. Study on veterinary antibiotic drugs handling and utilization in and around Holeta: School of Veterinary Medicine, Wolaita Sodo University, Ethiopia. Journal of Veterinary Medicine and Animal Health. 2018.

5. Ashine TB. Study on veterinary antibiotic drugs handling and utilization in and around Holeta: School of Veterinary Medicine, Wolaita Sodo University,
Ethiopia. Journal of Veterinary Medicine and Animal Health. 2018; 10: 55-59.

6. Tafese W. (DVM) System of measurement, Drug Formulation and Strength of solution veterinary drug and feed administration and control authority Adama. 2019; 1-30.

7. Witkamp RF. Genomics and systems biology-how relevant are the developments to veterinary pharmacology, toxicology and therapeutics? J Vet Pharmacol Ther. 2005; 28: 235-245.

8. Woods DJ, Knauer CS. Discovery of veterinary antiparasitic agents in the $21^{\text {st }}$ century: a view from the industry. Int J Parasitol. 2010; 40: 1177-1181.

9. Meinke PT. Perspectives in animal health: old targets and new opportunities. J Med Chem. 2001; 44: 641-659.

10. FAO. "Revising Veterinary Legislation", FAO Terminal Statement prepared for the Government of Rwanda. 2003.

11. Fingleton J. Legislation for Veterinary Drugs Control: Fao Legalpapers. 2004

12. WHO: Joint FAO/WHO Expert Committee on Feed Additives (JECFA). Toxicological evaluation of certain vet drug residues in food: monograph prepared by the thirty second meeting of the joint FAO/WHO Expert Committee on Food Additives. 1998.

13. Brahma D, Marak M, Wahlang J. Rational Use of Drugs and Irrational Drug Combinations. Internet J. Pharmacol. 2012; 10.

14. Albonico M, Behnke J, Bundy D, Coles G, Churcher T, Drake L, et al. Monitoring Anthelmintic Efficacy for Soil Transmitted Helminths (STH) . 2008.

15. Menzir Awake (DVM). Principles and Process of Veterinary Drugs Dispensing Practice Vet Drug and Institutions Inspector Amhara Region Branch Office. 2019.

16. Tesega B. Rational veterinary drug use: Its significance in public health. Department of Biomedical Sciences, College of Veterinary Medicine and Agriculture, Addis Ababa University, PO-Box 34, Bishoftu, Ethiopia. Journal of Veterinary Medicine and Animal Health. 2014; 6.

17. Beyene T. Rational veterinary drug use: Its significance in public health Department of Biomedical Sciences, College of Veterinary Medicine and Agriculture, Addis Ababa University, PO-Box 34, Bishoftu, Ethiopia. Journal of Veterinary Medicine and Animal Health. 2014; 6.

18. Eckhoff Gary A. "Prescription Writing for the Veterinarian," lowa State University Veterinarian. 1976; 38.

19. Wagari T. Rational use of veterinary drugs, drug source and development, veterinary drug and feed administration and control authority. 2010; 1-20.

20. Hadush A. Veterinary drug handling, management and supply chain assessment in afar pastoral regionof north east Ethiopia. American journal oof bioscience and bioengineering. 2015; 3: 142-148.

21. Fowler et al. A survey of veterinary antimicrobial prescribing practices, Washington State 2015. Vet Rec. 2016; 179: 651.

22. Guidelines for Prescribing, Authorising and Dispensing Veterinary Medicines Ed. M.P. Bond, Australian Veterinary Association Ltd. PO Box 4257 Kingston ACT 2604. 2005.

23. Gracey J, Collins D, Hvey R. meat hygiene. $10^{\text {th }}$ edition. Harcourt Brace press. London. 1999: 299: 319.

24. Woodward KN. Veterinary pharmacovigiliance adverce reactions to veterinary medicine products: john wily and sons Ltd, southern gate, chichester, west sussey po19 85Q, Blackwell, UK. 2009.

25. Aarestrup FM, Wegener $\mathrm{HC}$ and Collignon P. Resistance in Bacteria of the food chain epidemiology and control strategies. Expert Rev. Anti. Infect. Ther. 2008; 6: 733-750.

26. Wall BA, Mateus A, Marshall L, Pfeiffer DU, Lubroth J, Ormel HJ, et al. Drivers, Dynamics and Epidemiology of Antimicrobial Resistance in Animal Production, food and agriculture organization of the united nation. 2016.

27. Ernest J. Resistance to antimicrobials in humans and animals. Biomed J. 2005; 331: 1219-1220. 
28. Van Wyk JA. Refugia-overlooked as perhaps the most potent factor concerning the development of anthelmintic resistance. Onderstepoor Journal of Veterinary Research. 2001; 68: 55-67.

29. Madigan MT, Martinko JM, Stahl D, Clark DP. Brock Biology of Microorganisms. 13 Ed. San Francisco: Person Education. 2012.

30. Ketrin Cristina Da SILVA, Terezinha KNÖBL and Andrea Micke MORENO Antimicrobial Resistance In Veterinary Medicine: 2013. Mechanisms And Bacterial Agents With The Greatest Impact On Human Health, Brazilian Journal Of Veterinary Research And Animal Science. 2013.

31. Furgasa W, Beyene T. Review on Antimicrobial Usage in Food Animals: Challenges in Ethiopia and its Future Perspectives: Scholars Journal of Agriculture and Veterinary Sciences (SJAVS), A Unit of Scholars Academic and Scientific Society. 2018.

32. Impact on public health and animal health of the use of antibiotics in animals 2019.

33. Barry Bousfield and Richard Brown. Veterinary Drugs: Agriculture, Fisheries and Conservation Department Room 708, 7/F Cheung Sha Wan Government Offices, 303 Cheung Sha Wan Road, Kowloon. 2012.

34. Sneeringer S, Macdonald J, Key N, Mcbride W, Mathews K. Economics of Antibiotic Use in U.S. Livestock Production, ERR-200, U.S. Department of Agriculture, Economic Research Service, November 2015.

35. Harrison EM, Paterson GK, Holden MTG, Larsen J, Stegger M, Larsen AR, et al. "Whole genome sequencing identifies zoonotic transmission of MRSA isolates with the novel MecA homologue mecC." EMBO Molecular Medicine. 2013: 509-515.

36. Koricho TD, Seid M. Implication and Tackling Approaches of Veterinary Antibiotic Drug Resistance: Journal of Dairy \& Veterinary Sciences. 2018; 8.

37. Eric S. Risk assessment $t$ of veterinary drug residues in edible animal food: role of international agencies joint FAO/IAEA international symposium on food safety and quality: applications of nuclear and related techniques. 2014. 